\title{
1
}

\section{AZOBENZENE POLYMERS FOR PHOTONIC APPLICATIONS}

Kevin G. Yager and Christopher J. Barrett

\subsection{INTRODUCTION TO AZOBENZENE}

Azobenzene, with two phenyl rings separated by an azo $(-\mathrm{N}=\mathrm{N}-)$ bond, serves as the parent molecule for a broad class of aromatic azo compounds. These chromophores are versatile molecules, and have received much attention in research areas both fundamental and applied. The strong electronic absorption maximum can be tailored by ring substitution to fall anywhere from the ultraviolet (UV) to visible red regions, allowing chemical fine-tuning of color. This, combined with the fact that these azo groups are relatively robust and chemically stable, has prompted extensive study of azobenzene-based structures as dyes and colorants. The rigid mesogenic shape of the molecule is well suited to spontaneous organization into liquid crystalline (LC) phases, and hence polymers doped or functionalized with azobenzene-based chromophores (azo polymers) are common as LC media. With appropriate electron-donor-acceptor ring substitution, the $\pi$ electron delocalization of the extended aromatic structure can yield high optical nonlinearity, and zo chromophores have seen extensive study for nonlinear optical applications as well. One of the most interesting properties of these chromophores however, and the main subject of this review, is the readily induced and reversible isomerization about the azo bond between the trans and cis geometric isomers and the geometric changes that result when azo chromophores are incorporated into polymers and other materials. This light-induced interconversion allows systems incorporating azobenzenes to be used as photoswitches, effecting rapid and reversible control over a variety of chemical, mechanical, electronic, and optical properties. 
Perhaps of a range as wide as the interesting phenomena displayed by azo aromatic compounds is the variety of molecular systems into which these chromophores can be incorporated. In addition to LC media and amorphous glasses, azobenzenes can be incorporated into self-assembled monolayers and superlattices, sol-gel silica glasses, and various biomaterials. The photochromic or photoswitchable nature of azobenzenes can also be used to control the properties of novel small molecules, using an attached aromatic azo group. A review will be presented here of the photochemical and photophysical nature of chromophores in host polymers, the geometric and orientational consequences of this isomerization, and some of the interesting ways in which these phenomena have been expolited recently to exert control over solution and biochemical properties using light. This photoisomerization can be exploited as a photoswitch to orient the chromophore (which induces birefringence), or even to perform all-optical surface topography patterning. These photomotions enable many interesting applications, ranging from optical components and lithography to sensors and smart materials.

\subsubsection{Azobenzene Chromophores}

In this text, as in most on the subject, we use "azobenzene" and "azo" in a general way: to refer to the class of compounds that exhibit the core azobenzene structure, with different ring substitution patterns (even though, strictly, these compounds should be referred to as "diazenes"). There are many properties common to nearly all azobenzene molecules. The most obvious is the strong electronic absorption of the conjugated $\pi$ system. The absorption spectrum can be tailored, via the ring substitution pattern, to lie anywhere from the UV to the visible red region. It is not surprising that azobenzenes were originally used as dyes and colorants, and up to $70 \%$ of the world's commercial dyes are still azobenzene-based (Zollinger, 1987, 1961). The geometrically rigid structure and large aspect ratio of azobenzene molecules make them ideal mesogens: azobenzene small molecules and polymers functionalized with azobenzene can exhibit LC phases (Möhlmann and van der Vorst, 1989; Kwolek et al., 1985). The most startling and intriguing characteristic of the azobenzenes is their highly efficient and fully reversible photoisomerization. Azobenzenes have two stable isomeric states, a thermally stable trans configuration and a metastable cis form. Remarkably, the azo chromophore can interconvert between these isomers upon absorption of a photon. For most azobenzenes, the molecule can be optically isomerized from trans to cis with light anywhere within the broad absorption band, and the molecule will subsequently thermally relax back to the trans state on a timescale dictated by the substitution pattern. This clean photochemistry is central to azobenzene's potential use as a tool for nanopatterning.

Azobenzenes can be separated into three spectroscopic classes, well described by Rau (1990): azobenzene-type molecules, aminoazobenzene-type molecules, and pseudo-stilbenes (refer to Fig. 1.1 for examples). The particulars of their absorption spectra (shown in Fig. 1.2) give rise to their prominent colors: yellow, orange, and red, respectively. Many azos exhibit absorption characteristics similar to the unsubstituted azobenzene archetype. These molecules exhibit 
<smiles>c1ccc(/N=N/c2ccccc2)cc1</smiles>

(a)<smiles>Nc1ccc(/N=N/c2ccccc2)cc1</smiles><smiles>Nc1ccc(N=Nc2ccc([N+](=O)[O-])cc2)cc1</smiles>

(b)

(c)

Figure 1.1. Examples of azomolecules classified as (a) azobenzenes, (b) aminoazobenzenes, and (c) pseudo-stilbenes.

a low intensity $n \rightarrow \pi^{*}$ band in the visible region and a much stronger $\pi \rightarrow \pi^{*}$ band in the UV. Although the $n \rightarrow \pi *$ is symmetry-forbidden for trans-azobenzene $\left(\mathrm{C}_{2 \mathrm{~h}}\right)$, vibrational coupling and some extent of nonplanarity nevertheless make it observable (Rau, 1968).

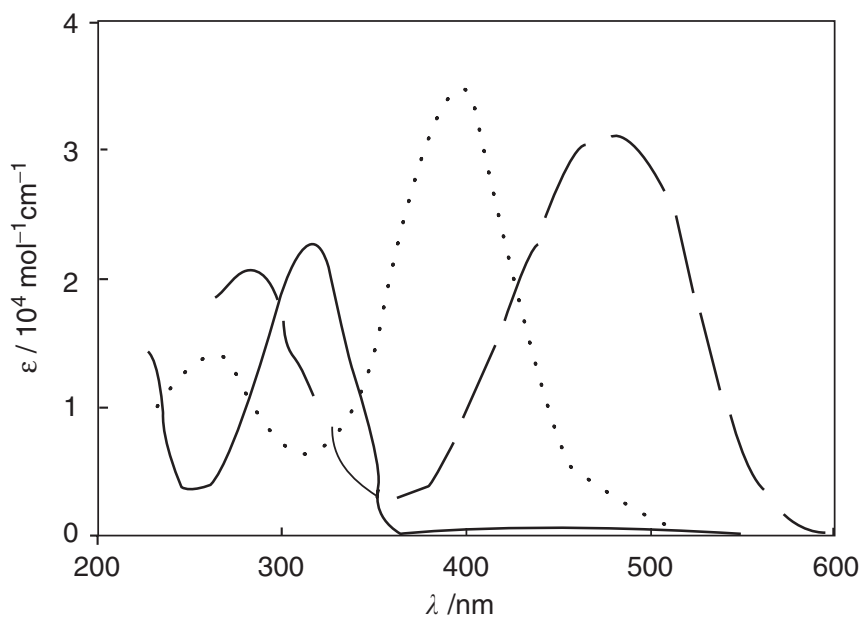

Figure 1.2. Schematic of typical absorbance spectra for trans-azobenzenes. The azobenzene-type molecules (solid line) have a strong absorption in the UV, and a low intensity band in the visible (barely visible in the graph). The aminoazobenzenes (dotted line) and pseudo-stilbenes (dashed line) typically have strong overlapped absorptions in the visible region. 
Adding substituents to the azobenzene rings may lead to minor or major changes in spectroscopic character. Of particular interest is ortho- or parasubstitution with an electron-donating group (usually an amino, $-\mathrm{NH}_{2}$ ), which results in a new class of compounds. In these aminoazobenzenes, the $n \rightarrow \pi^{*}$ and $\pi \rightarrow \pi^{*}$ bands are much closer. In fact, the $n \rightarrow \pi^{*}$ may be completely buried beneath the intense $\pi \rightarrow \pi^{*}$. Although azobenzenes are fairly insensitive to solvent polarity, aminoazobenzene absorption bands shift to higher energy in nonpolar solvents and shift to lower energy in polar solvents. Substituting azobenzene at the 4 and $4^{\prime}$ positions with an electron-donor and an electron-acceptor (such as an amino and a nitro, $-\mathrm{NO}_{2}$, group) leads to a strongly asymmetric electron distribution (often referred to as a "push-pull" substitution pattern). This shifts the $\pi \rightarrow \pi *$ absorption to lower energy, toward the red and past the $n \rightarrow \pi^{*}$. This reversed ordering of the absorption bands defines the third spectroscopic class, the pseudo-stilbenes (in analogy to stilbene, phenyl $-\mathrm{C}=\mathrm{C}-$ phenyl). The pseudo-stilbenes are very sensitive to local environment, which can be useful in some applications.

Especially in condensed phases, the azos are also sensitive to packing and aggregation. The $\pi-\pi$ stacking gives rise to shifts of the absorption spectrum. If the azo dipoles have a parallel (head-to-head) alignment, they are called J-aggregates, and give rise to a redshift of the spectrum (bathochromic) as compared with the isolated chromophore. If the dipoles are antiparallel (head-to-tail), they are called $\mathrm{H}$-aggregates and lead to a blueshift (hypsochromic). Fluorescence is seen in some aminoazobenzenes and many pseudo-stilbenes but not in azobenzenes, whereas phosphorescence is absent in all the three classes. By altering the electron density, the substitution pattern necessarily affects the dipole moment, and in fact all the higher order multipole moments. This becomes significant in many nonlinear optical (NLO) studies. For instance, the chromophore's dipole moment can be used to orient with an applied electric field (poling), and the higher order moments of course define the molecule's nonlinear response (Delaire and Nakatani, 2000). In particular, the strongly asymmetric distribution of the delocalized electrons that results from push-pull substitution results in an excellent NLO chromophore.

\subsubsection{Azobenzene Photochemistry}

Key to some of the most intriguing results and interesting applications of azobenzenes is the facile and reversible photoisomerization about the azo bond, converting between the trans $(E)$ and cis $(Z)$ geometric isomers (Fig. 1.3). This photoisomerization is completely reversible and free from side reactions, prompting Rau to characterize it as "one of the cleanest photoreactions known." (Rau, 1990) The trans isomer is more stable by $\sim 50 \mathrm{~kJ} \mathrm{~mol}^{-1}$ (Mita et al., 1989; Schulze et al., 1977), and the energy barrier to the photoexcited state (barrier to isomerization) is on the order of $200 \mathrm{~kJ} \mathrm{~mol}^{-1}$ (Monti et al., 1982). Thus, in the dark, most azobenzene molecules will be found in the trans form. On absorption of a photon (with a wavelength in the trans absorption band), the azobenzene will convert, with high efficiency, into the cis isomer. A second wavelength of light (corresponding to the cis absorption band) can cause the back-conversion. 
<smiles>[GeH3]c1ccc(N=Nc2ccccc2)cc1</smiles>

(a)

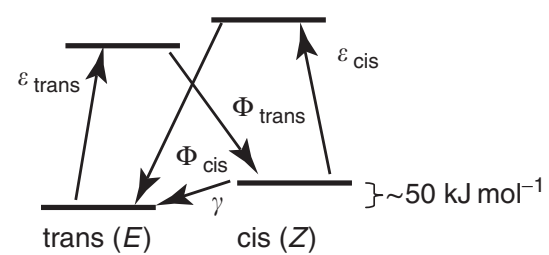

(b)

Figure 1.3. (a) Azobenzene can convert between trans and cis states photochemically and relaxes to the more stable trans state thermally. (b) Simplified state model for azobenzenes. The trans and cis extinction coefficients are denoted by $\varepsilon_{\text {trans }}$ and $\varepsilon_{\text {cis. }}$. The $\Phi$ refer to quantum yields of photoisomerization, and $\gamma$ is the thermal relaxation rate constant.

These sphotoisomerizations usually have picosecond timescales (Lednev et al., 1996; Kobayashi et al., 1979). Alternately, azos will thermally reconvert from the cis into trans state, with a timescale ranging from milliseconds to hours, depending on the substitution pattern and local environment. More specifically, the lifetimes for azobenzenes, aminoazobenzenes, and pseudo-stilbenes are usually on the order of hours, minutes, and seconds, respectively. The energy barrier for thermal isomerization is on the order of $90 \mathrm{~kJ} \mathrm{~mol}^{-1}$ (Brown and Granneman, 1975; Haberfield et al., 1975). Considerable work has gone into elongating the cis lifetime, with the goal of creating truly bistable photoswitchable systems. Bulky ring substituents can be used to hinder the thermal back reaction. For instance, a polyurethane main-chain azo exhibited a lifetime of 4 days (thermal rate constant of $k=2.8 \times 10^{-6} \mathrm{~s}^{-1}$, at $3^{\circ} \mathrm{C}$ ) (Lamarre and Sung, 1983), and an azobenzene parasubstituted with bulky pendants had a lifetime of 60 days $\left(k<2 \times 10^{-7} \mathrm{~s}^{-1}\right.$, at room temperature) (Shirota et al., 1998). The conformational strain of macrocylic azo compounds can also be used to lock the cis state, where lifetimes of 20 days $\left(k=5.9 \times 10^{-7} \mathrm{~s}^{-1}\right)$ (Norikane et al., 2003), 1 year (half-life 400 days, $k=2 \times 10^{-8} \mathrm{~s}^{-1}$ ) (Rottger and Rau, 1996; Rau and Roettger, 1994), or even 6 years $\left(k=4.9 \times 10^{-9} \mathrm{~s}^{-1}\right)$ (Nagamani et al., 2005) were observed. Similarly, using the hydrogen bonding of a peptide segment to generate a cyclic structure, a cis lifetime of $\sim 40$ days $\left(k=2.9 \times 10^{-7} \mathrm{~s}^{-1}\right)$ was demonstrated (Vollmer et al., 1999). Of course, one can also generate a system that starts in the cis state and where isomerization (in either direction) is completely hindered. For instance, attachment to a surface (Kerzhner et al., 1983), direct synthesis of ringlike azo molecules (Funke and Gruetzmacher, 1987), and crystallization of the cis form (Hartley, $1938,1937)$ can be used to maintain one state, but such systems are obviously not bistable photoswitches.

A bulk azo sample or solution under illumination will achieve a photostationary state, with a steady-state trans-cis composition based on the competing 
effects of photoisomerization into the cis state, thermal relaxation back to the trans state, and possibly cis reconversion upon light absorption. The steady-state composition is unique to each system, as it depends on the quantum yields for the two processes $\left(\Phi_{\text {trans }}\right.$ and $\left.\Phi_{\text {cis }}\right)$ and the thermal relaxation rate constant. The composition also depends on irradiation intensity, wavelength, temperature, and the matrix (gas phase, solution, liquid crystal, sol-gel, monolayer, polymer matrix, etc.). Azos are photochromic (their color changes on illumination), since the effective absorption spectrum (a combination of the trans and cis spectra) changes with light intensity. Thus absorption spectroscopy can be conveniently used to measure the cis fraction in the steady state (Rau et al., 1990; Fischer, 1967), and the subsequent thermal relaxation to an all-trans state (Beltrame et al., 1993; Hair et al., 1990; Eisenbach, 1980a; Gabor and Fischer, 1971). Nuclear magnetic resonance (NMR) spectroscopy can also be used (Magennis et al., 2005). Under moderate irradiation, the composition of the photostationary state is predominantly cis for azobenzenes, mixed for aminoazobenzenes, and predominantly trans for pseudo-stilbenes. In the dark, the cis fraction is below most detection limits, and the sample can be considered to be in an all-trans state. Isomerization is induced by irradiating with a wavelength within the azo's absorption spectrum, preferably close to $\lambda_{\max }$. Modern experiments typically use laser excitation with polarization control, delivering on the order of $1-100 \mathrm{~mW} \mathrm{~cm}^{-2}$ of power to the sample. Various lasers cover the spectral range of interest, from the UV $\left(\mathrm{Ar}^{+}\right.$line at $\left.350 \mathrm{~nm}\right)$ through blue $\left(\mathrm{Ar}^{+}\right.$at $\left.488 \mathrm{~nm}\right)$, green $\left(\mathrm{Ar}^{+}\right.$at $514 \mathrm{~nm}, \mathrm{YAG}$ at $532 \mathrm{~nm}, \mathrm{HeNe}$ at $\left.545 \mathrm{~nm}\right)$, and into the red $(\mathrm{HeNe}$ at $633 \mathrm{~nm}, \mathrm{GaAs}$ at $675 \mathrm{~nm})$.

The ring substitution pattern affects both the trans and the cis absorption spectra, and for certain patterns, the absorption spectra of the two isomers overlap significantly (notably for the pseudo-stilbenes). In these cases, a single wavelength of light effectuates both the forward and reverse reaction, leading to a mixed stationary state and continual interconversion of the molecules. For some interesting azobenzene photomotions, this rapid and efficient cycling of chromophores is advantageous, whereas in cases where the azo chromophore is used as a switch, it is clearly undesirable.

The mechanism of isomerization has undergone considerable debate. Isomerization takes place either through a rotation about the $\mathrm{N}-\mathrm{N}$ bond, with rupture of the $\pi$ bond, or through inversion, with a semilinear and hybrizidized transition state, where the $\pi$ bond remains intact (refer to Fig. 1.4). The thermal backrelaxation is agreed to be via rotation, whereas for the photochemical isomerization, both mechanisms appear viable (Xie et al., 1993). Historically, the rotation mechanism (as necessarily occurs in stilbene) was favored for photoisomerization, with some early hints that inversion may be contributing (Gegiou et al., 1968). More recent experiments, based on matrix or molecular constraints to the azobenzene isomerization, strongly support inversion (Altomare et al., 1997; Liu et al., 1992; Naito et al., 1991; Rau and Lueddecke, 1982). Studies using picosecond Raman and femtosecond fluorescence show a double bond $(\mathrm{N}=\mathrm{N})$ in the excited state, confirming the inversion mechanism (Fujino et al., 2001; Fujino 


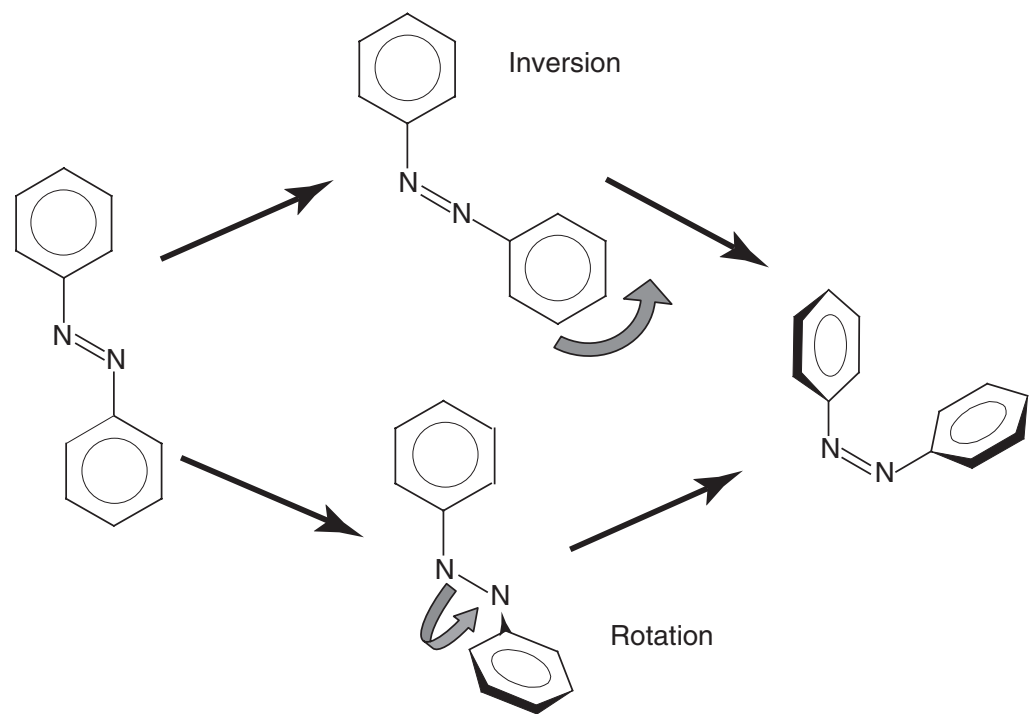

Figure 1.4. The mechanism of azobenzene isomerization proceeds either via rotation or inversion. The cis state has the phenyl rings tilted at $90^{\circ}$ with respect to the CNNC plane.

and Tahara, 2000). In contrast, Ho et al. (2001) found evidence that the pathway is compound-specific: a nitro-substituted azobenzene photoisomerized via the rotation pathway. Furthermore, ab initio and density functional theory calculations indicate that both pathways are energetically accessible, although inversion is preferred (Angeli et al., 1996; Jursic, 1996). Thus, both mechanisms may be competing, with a different one dominating depending on the particular chromophore and environment. The emerging consensus nevertheless appears to be that inversion is the dominant pathway for most azobenzenes (Ikeda and Tsutsumi, 1995). The availability of the inversion mechanism explains how azos are able to isomerize easily even in rigid matrices, such as glassy polymers, since the inversion mechanism has a much smaller free volume requirement than rotation.

The thermal back-relaxation is generally first order, although a glassy polymer matrix can lead to anomalously fast decay components (Barrett et al., 1995, 1994; Paik and Morawetz, 1972; Priest and Sifain, 1971), attributed to a distribution of chromophores in highly strained configurations. Higher matrix crystallinity increases the rate of decay (Sarkar et al., 2001). The decay rate can act as a probe of local environment and molecular conformation (Tanaka et al., 2004; Norman and Barrett, 2002). The back-relaxation of azobenzene is acid catalyzed (Rau et al., 1981), although strongly acidic conditions will lead to side reactions (Hartley, 1938). For the parent azobenzene molecule, quantum yields (which can be indirectly measured spectroscopically (Shen and Rau, 1991; Priest and Sifain, 1971; Malkin and Fischer, 1962) are on the order of 0.6 for the trans $\rightarrow$ cis 
photoconversion, and 0.25 for the back photoreaction. Solvent has a small effect, increasing the trans $\rightarrow$ cis and decreasing the cis $\rightarrow$ trans yield as polarity increases (Bortolus and Monti, 1979). Aminoazobenzenes and pseudo-stilbenes isomerize very quickly and can have quantum yields as high as $0.7-0.8$.

\subsubsection{Classes of Azobenzene Systems}

Azobenzenes are robust and versatile moieties, and have been extensively investigated as small molecules, pendants on other molecular structures, or incorporated (doped or covalently bound) into a wide variety of amorphous, crystalline, or LC polymeric systems. Noteworthy examples include self-assembled monolayers and superlattices (Yitzchaik and Marks, 1996), sol-gel silica glasses (Levy and Esquivias, 1995), and biomaterials (Gallot et al., 1996; Willner and Rubin, 1996; Sisido et al., 1991a). A number of small molecules incorporating azobenzene have been synthesized, including crown ethers (Shinkai et al., 1983), cyclodextrins (Jung et al., 1996; Yamamura et al., 1996), proteins such as bacteriorhodopsin (Singh et al., 1996), and three-dimensional (3-D) polycyclics such as cubane (Chen et al., 1997b) and adamantane (Chen et al., 1995). Typically, azo chromophores are embedded in a solid matrix for studies and devices. As a result, matrix effects are inescapable: the behavior of the chromophore is altered due to the matrix, and in turn, the chromophore alters the matrix (Ichimura, 2000). Although either could be viewed as a nuisance, both are in fact useful: the chromophore can be used as a probe of the matrix (free volume, polarizability, mobility, etc.), and when the matrix couples to chromophore motion, molecular motions can be translated to larger length scales. Thus, the incorporation strategy is critical to exploiting azobenzene's unique behavior.

1.1.3.1. Amorphous Polymer Thin Films. Doping azobenzenes into polymer matrices is a convenient inclusion technique (Birabassov et al., 1998; Labarthet et al., 1998). These "guest-host" systems can be cast or spin-coated from solution mixtures of polymer and azo small molecules, where the azo content in the thin film is easily adjusted via concentration. Although doping leaves the azo chromophores free to undergo photoinduced motion unhindered, it has been found that many interesting photomechanical effects do not couple to the matrix in these systems. Furthermore, the azo mobility often leads to instabilities, such as phase separation or microcrystallization. Thus, one of the most attractive methodologies for incorporating azobenzene into functional materials is by covalent attachment to polymers. The resulting materials benefit from the inherent stability, rigidity, and processability of polymers, in addition to the unusual photoresponsive behavior of the azo moieties. Both side-chain and main-chain azobenzene polymers have been prepared (Viswanathan et al., 1999) (Fig. 1.5). Reported synthetic strategies involve either polymerizing azobenzene-functionalized monomers (Ho et al., 1996; Natansohn et al., 1992) or postfunctionalizing 

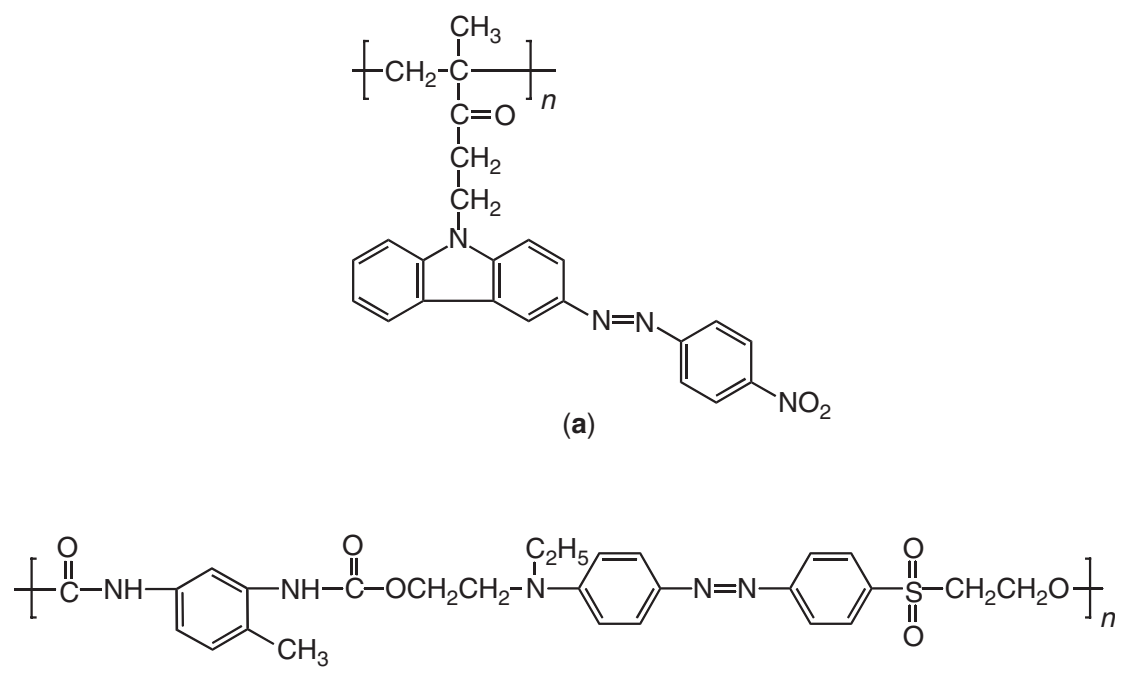

(b)

Figure 1.5. Examples of azo polymer structures, showing that both (a) side-chain and (b) main-chain architectures are possible.

a polymer that has an appropriate pendant group (usually a phenyl) (Wang et al., $1997 \mathrm{a}, \mathrm{b}, \mathrm{c})$. The first method is preferred for its simplicity and control of sequence distribution. The second takes advantage of commonly available starting materials, but may require more reaction steps. Many different backbones have been used as scaffolds for azo moieties, including imides (Agolini and Gay, 1970), esters (Anderle et al., 1989), urethanes (Furukawa et al., 1967), ethers (Bignozzi et al., 1999), organometallic ferrocene polymers (Liu et al., 1997), dendrimers (Junge and McGrath, 1997; Mekelburger et al., 1993), and even conjugated polydiacetylenes (Sukwattanasinitt et al., 1998), polyacetylenes (Teraguchi and Masuda, 2000), and main-chain azobenzenes (Izumi et al., 2000a,b). The most common azo polymers are acrylates (Morino et al., 1998), methacrylates (Altomare et al., 2001), and isocyanates (Tsutsumi et al., 1996). Thin films are usually prepared by spincoating (Han and Ichimura, 2001; Blinov et al., 1998; Weh et al., 1998; Ichimura et al., 1996), although there are also many examples of using solvent evaporation, the Langmuir-Blodgett technique (Silva et al., 2002; Razna et al., 1999; Jianhua et al., 1998; Seki et al., 1993), and self-assembled monolayers (Evans et al., 1998). Spin-cast films are typically annealed above the polymer glass transition temperature $\left(T_{\mathrm{g}}\right)$ to remove residual solvent and erase any hydrodynamically induced anisotropy. Recently molecular glasses have been investigated as alternatives to amorphous polymer systems (Mallia and Tamaoki, 2003). These monodisperse systems appear to maintain the desirable photomotions and photoswitching properties, while allowing precise control of molecular architecture and thus material properties (Naito and Miura, 1993). 
1.1.3.2. Liquid Crystals. Azobenzenes are anisotropic, rigid molecules and as such are ideal candidates to act as mesogens: molecules that form LC mesophases. Many examples of small-molecule azobenzene liquid crystals have been studied. Some azo polymers also form LC phases (refer to Fig. 1.6 for a typical structure). For side-chain azobenzenes, a certain amount of mobility is required for LC phases to be present; as a rule, if the tether between the chromophore and the backbone is less than 6 alkyl units long, the polymer will exhibit an amorphous and isotropic solid-state phase, whereas if the spacer is longer, LC phases typically form. The photoisomerization of azobenzene leads to modification of the phase and alignment (director) in LC systems (Shibaev et al., 2003; Ichimura, 2000). The director of a liquid crystal phase can be modified by orienting chromophores doped into the phase (Sun et al., 1992; Anderle et al., 1991) by using an azobenzene-modified "command surface" (Chen and Brady, 1993; Ichimura et al., 1993; Gibbons et al., 1991), using azo copolymers (Wiesner et al., 1991), and, of course, in pure azobenzene LC phases (Hvilsted et al., 1995; Stumpe et al., 1991). One can force the LC phase to adopt an in-plane order (director parallel to surface), homeotropic alignment (director perpendicular to surface), tilted or even biaxial orientation (Yaroschuk et al., 2001). These changes are fast and reversible. Although the trans-azobenzenes are excellent mesogens, the cis-azos typically are not. If even a small number of azomolecules are

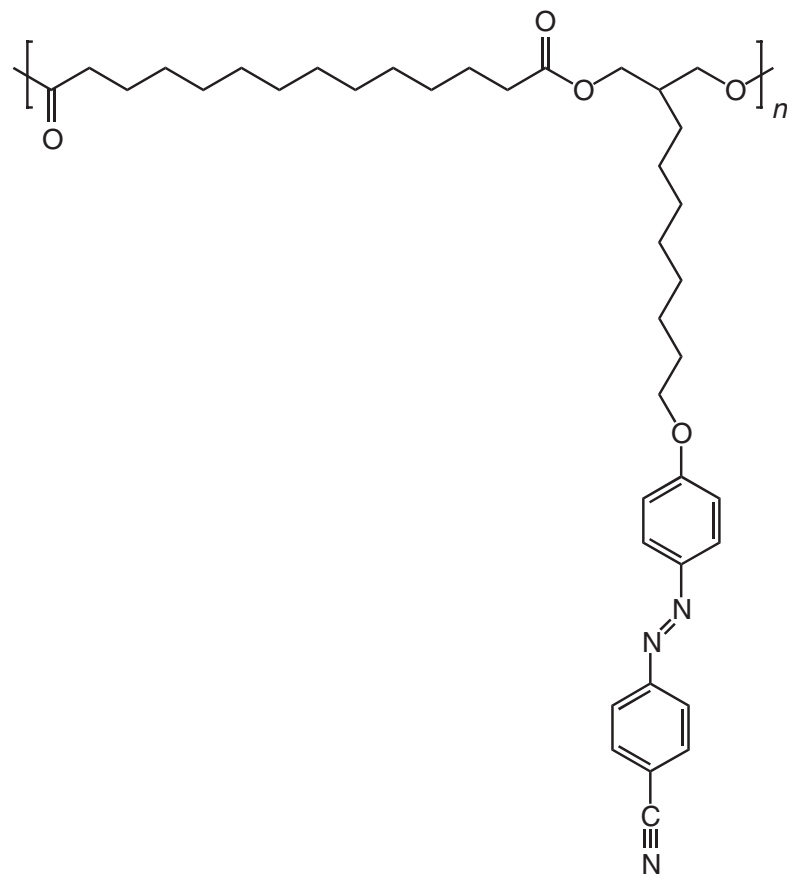

Figure 1.6. A typical liquid-crystalline side-chain azobenzene polymer. 
distributed in an LC phase, trans $\rightarrow$ cis isomerization can destabilize the phase by lowering the nematic-to-isotropic phase transition temperature (Eich and Wendorff, 1990). This enables fast isothermal photocontrol of phase transitions (Kato et al., 1996; Hayashi et al., 1995; Ikeda and Tsutsumi, 1995; Ikeda et al., 1990). Since these modulations are photoinitiated, it is straightforward to create patterns (Shannon et al., 1994). These LC photoswitching effects are obviously attractive in many applications, such as for display devices, optical memories (Gibbons et al., 1991), electro-optics (Luk and Abbott, 2003), and modulating the polarization of ferroelectric liquid crystals (Fischer et al., 1997; Ikeda et al., 1993).

1.1.3.3. Dendrimers. Dendrimers have been investigated as unique structures to exploit and harness azobenzene's photochemistry (Momotake and Arai, 2004a,b; Villavicencio and McGrath, 2002). Dendritic and branched molecular architectures can have better solubility properties and can be used to control undesired aggregation, resulting in higher quality films for optical applications (Campbell et al., 2006; Ma et al., 2002). Dendrimers with strongly absorbing pendants can act as antenna, harvesting light and making it available, via intramolecular energy transfer, to the dendrimer core. In dendrimers with azo cores, this allows for the activation of isomerization using a wavelength outside of the azo-absorption band (since the dendrimer arms absorb and transfer energy to the core) (Aida et al., 1998; Jiang and Aida, 1997). Furthermore, the configurational change that results from the core isomerization will translate into a larger scale geometric change. For instance, in a dendrimer with three azobenzene arms (Fig. 1.7), the various isomerization combinations (EEE, EEZ, EZZ, and ZZZ) could all be separated by thin-layer chromatography because of their different physical properties (Junge and McGrath, 1999). The conformational change associated with isomerization modifies (typically reduces) the hydrodynamic volume, with the specific extent of conformational change depending strongly on where the azo units are incorporated ( $\mathrm{Li}$ and McGrath, 2000).

1.1.3.4. Polyelectrolyte Multilayers. A new facile and versatile film preparation technique, layer-by-layer electrostatic self-assembly, has become the subject of intensive research since its introduction by Decher (Decher, 1997; Decher and Schmitt, 1992; Decher and Hong, 1991; Decher et al., 1991). In this technique, a charged or hydrophilic substrate is immersed in a solution of charged polymers (polyelectrolytes), which adsorb irreversibly onto the substrate. After rinsing, the substrate is then immersed in a solution containing a polyelectrolyte of opposite charge, which adsorbs electrostatically to the charged polymer monolayer. Because each layer of adsorbed polymer reverses the surface charge, one can build up an arbitrary number of alternating polycation-polyanion layers. These polyelectrolyte multilayers (PEMs) are easy to prepare, use benign (all-aqueous) chemistry, and are inherently tunable (Decher et al., 1998; Hammond, 1999; Knoll, 1996). Specifically, by adjusting the ionic strength (Steitz et al., 2000; Linford et al., 1998; Lösche et al., 1998; Sukhorukov et al., 1996) or pH (Burke and Barrett, 2003a; Chung and Rubner, 2002; Wang et al., 2002; Shiratori and 


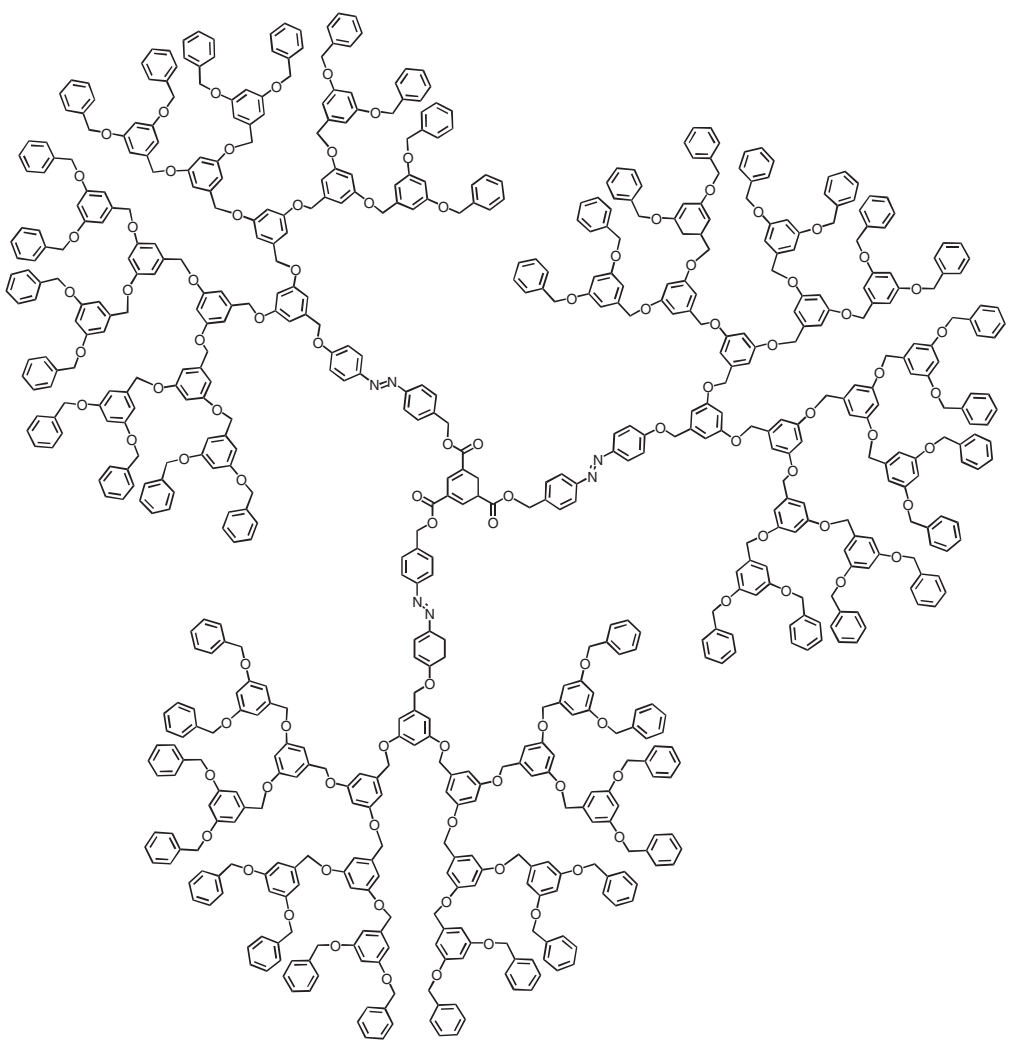

Figure 1.7. An azobenzene dendrimer containing three azo moieties. Each chromophore has two isomerization states (trans and cis), leading to four distinct photoisomers for the dendrimer molecule. All four isomers have different physical properties.

Rubner, 2000) (in the case of "weak" polyelectrolytes) of the assembly solution, the polyelectrolyte chain conformation is modified, and hence the resulting film architecture is tuned. For instance, one can control thickness (Lösche et al., 1998; Dubas and Schlenoff, 1999), permeability (Rmaile and Schlenoff, 2003), morphology (Antipov et al., 2003; McAloney et al., 2003; Mendelsohn et al., 2000), and density (Dragan et al., 2003). Recently the technique has been modified to assemble the alternate layers using a spin-coater, which reduces the assembly times and adsorption solution volumes considerably (Chiarelli et al., 2001; Cho et al., 2001; Lee et al., 2003, 2001).

As a film preparation technique, this method has numerous advantages. The adsorption of the polymers is quasithermodynamic, with the chains adsorbing into a local minimum, which makes the films stable against many defects (dewetting, pinhole formation, etc.). Importantly, the technique is not limited to flat surfaces: any geometry that can be immersed in solution (or have solution flowed through) 
is suitable. Colloids have been efficiently coated with PEMs (Caruso, 2001; Sukhorukov et al., 1998b), and by dissolving the core one can also form hollow PEM microcapsules (Sukhorukov et al., 1998a). Multilayers can be formed on nearly any material (glass, quartz, silicon, most metals, etc.) and are robust against thermal and solvent treatment (Mermut and Barrett, 2001). One of the main interests in PEMs is due to their inherent biocompatibility (Richert et al., 2002): multilayers have been formed on enzyme microcrystals (Jin et al., 2001), used to encapsulate living cells (Diaspro et al., 2002) and coat arterial walls (Thierry et al., 2003). Perhaps the most useful feature of the multilayering technique is its ability to incorporate secondary functional groups into the thin film structure. The location of these functional units (which may be small molecules, pendants on the polyelectrolyte chains, or particles) within the multilayer stack can be controlled with subnanometer precision. A wide variety of functionalities have been demonstrated, including organic molecules (He et al., 2000a), synthetic polymers (Balasubramanian et al., 1998), biopolymers (Burke and Barrett, 2003b), natural proteins (Caruso and Möhwald, 1999), colloids (Lvov et al., 1997), inorganic nanoparticles (Kotov et al., 1995), clay platelets (Kleinfeld and Ferguson, 1994) (used as a nacre biomimic [Tang et al., 2003]), dendrimers (Watanabe and Regen, 1994), electrochemically active species (Knoll, 1996), functionalized $\mathrm{C}_{60}$ (Mattoussi et al., 2000), and even, counterintuitively, uncharged and nonpolar polymer chains (Rouse and Ferguson, 2002).

Many research groups have investigated the possibility of incorporating optically responsive azobenzene chromophores into the versatile PEM structures (examples presented in Fig. 1.8), including Advincula (Advincula et al., 2001, 2003; Advincula, 2002; Ishikawa et al., 2002), Kumar and Tripathy (Lee et al., 2000; Balasubramanian et al., 1998), Tieke (Ziegler et al., 2002; Toutianoush et al., 1999; Toutianoush and Tieke, 1998; ; Saremi and Tieke, 1998),

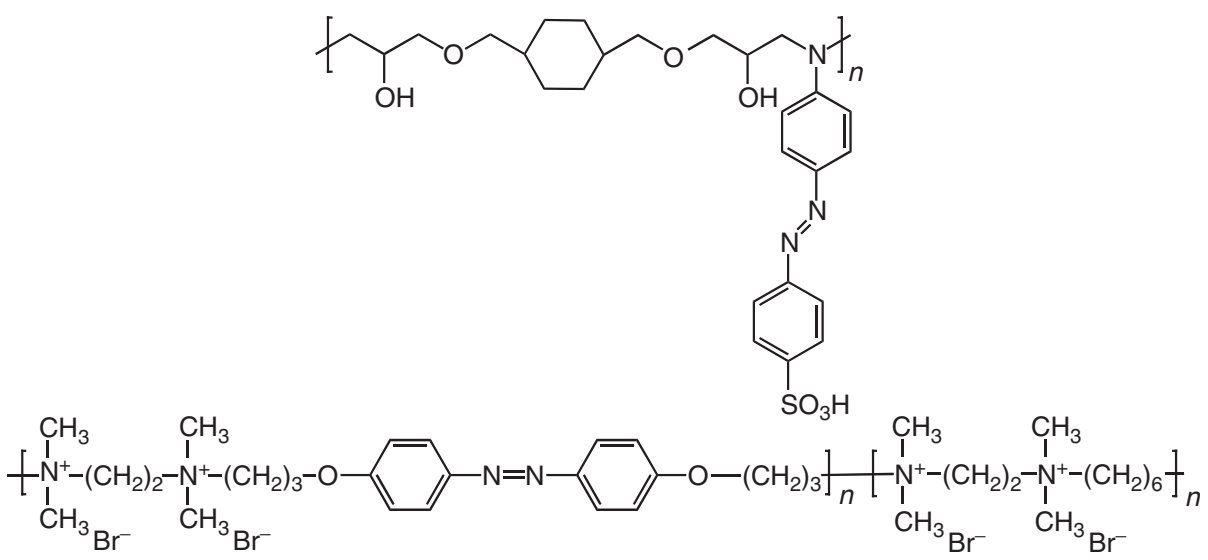

Figure 1.8. Examples of water-soluble azo polyelectrolytes, which can be used in the preparation of photoactive polyelectrolyte multilayers. 
Heflin (Van Cott et al., 2002), and Barrett (Mermut and Barrett, 2003; Mermut et al., 2003). In some cases, copolymers are synthesized, where some of the repeat units are charged groups and some are azo chromophores (Suzuki et al., 2003; Wu et al., 2001a). These materials may, however, have solubility issues, as the azo chromophore is typically not water-soluble. Efforts have therefore gone into synthesizing azo ionomers (Jung et al., 2002; Hong et al., 2000), or polymers where the charge appears on the azobenzene unit (Wang et al., 1998, 2004; Wu et al., 2001a). The azobenzene chromophore may also be created by postfunctionalization of an assembled PEM (Lee et al., 2000). Azobenzene-functionalized PEMs have demonstrated all of the unique photophysics associated with the chromophore, including induced birefringence (Ishikawa et al., 2002; Park and Advincula, 2002) and surface mass transport (Wang et al., 1998) (which is described in more detail in Section 1.3). It should be noted, however, that in general the quality of the patterning is lower (Wang et al., 2004), presumably because of the constraints to chain motion that the ionic "cross-links" engender. There are many examples of performing the multilayering with a polyelectrolyte and a small molecule azobenzene ionic dye (Dragan et al., 2003). In contrast to conventional doped systems, the chromophores in these systems do not suffer from aggregation instabilities (Advincula et al., 2001), and the azo photomotions do couple to the matrix, as evidenced by birefringence (dos Santos Jr. et al., 2003; Bian et al., 2000) and surface patterning (He et al., 2000a,b). These effects can again be attributed to the fact that the ionic attachment points act as cross-links in a dry PEM sample. The aggregation and photochemical behavior of the azo chromophore (absorbance spectrum, isomerization rate, etc.) vary depending on the nature of the counterpolymer (Dante et al., 1999) (and of course, is affected by any ionic ring substituent). These may be viewed as undesirable matrix effects, or as a way to tune the chromophore response. The multilayering technique does not offer the precision and reproducibility of conventional inorganic film preparation techniques. It is, however, simple, versatile, and offers the possibility of combining unique structures and functionalities (for instance, it has been used to create superhydrophobic surfaces [Zhai et al., 2004], to make azo photochromic hollow shells [Jung et al., 2002], and is amenable to patterning [Nyamjav and Ivanisevic, 2004]). Although it is unlikely to replace established techniques for high performance devices, it may find applications in certain niches (coatings, disposable electronics, biomedical devices, etc.).

\subsection{PHOTOINDUCED MOTIONS AND MODULATIONS}

Irradiation with light produces molecular changes in azobenzenes, and under appropriate conditions, these changes can translate into larger scale motions and even modulation of material properties. Following Natansohn and Rochon (2002), we will describe motions roughly in order of increasing size scale. However, since the motion on any size scale invariably affects (and is affected by) 
other scales, clear divisions are not possible. In all cases, some of the implicated applications, photoswitching, and photomodulations will be outlined.

\subsubsection{Molecular Motion}

The fundamental molecular photomotion in azobenzenes is the geometrical change that occurs on absorption of light. In cis-azobenzene, the phenyl rings are twisted at $90^{\circ}$ relative to the $\mathrm{C}-\mathrm{N}=\mathrm{N}-\mathrm{C}$ plane (Naito et al., 1991; Uznanski et al., 1991). Isomerization reduces the distance between the 4 and $4^{\prime}$ positions from $0.99 \mathrm{~nm}$ in the trans state to $0.55 \mathrm{~nm}$ in the cis state (Brown, 1966; Hampson and Robertson, 1941; de Lange et al., 1939). This geometric change increases the dipole moment: whereas the trans form has no dipole moment, the cis form has a dipole moment of 3.1 D (Hartley, 1937). The free volume requirement of the cis is larger than that of the trans (Naito et al., 1993), and it has been estimated that the minimum free volume pocket required to allow isomerization to proceed via the inversion pathway (Naito et al., 1991; Paik and Morawetz, 1972) is $0.12 \mathrm{~nm}^{3}$, and $\sim 0.38 \mathrm{~nm}^{3}$ via the rotation pathway (Lamarre and Sung, 1983). The effects of matrix free volume constraints on photochemical reactions in general have been considered (Weiss et al., 1993). The geometrical changes in azobenzene are very large, by molecular standards, and it is thus no surprise that isomerization modifies a wide host of material properties.

This molecular displacement generates a nanoscale force, which has been measured in single-molecule force spectroscopy experiments (Holland et al., 2003; Hugel et al., 2002) and compared with theory (Neuert et al., 2005). In these experiments, illumination causes contraction of an azobenzene polymer, showing that each chromophore can exert $\mathrm{pN}$ molecular forces on demand. A pseudorotaxane that can be reversibly threaded-dethreaded using light has been called an “artificial molecular-level machine”(Balzani et al., 2001; Asakawa et al., 1999). The ability to activate and power molecular-level devices using light is of course attractive since it circumvents the limitations inherent to diffusion or wiring. The fast response and lack of waste products in azo isomerization are also advantageous. Coupling these molecular-scale motions to do useful work is of course the next challenging step. Progress in this direction is evident from a wide variety of molecular switches that have been synthesized. For example, an azo linking two porphyrin rings enabled photocontrol of electron transfer (Tsuchiya, 1999). In another example, dramatically different hydrogen-bonding networks (intermolecular and intramolecular) can be favored on the basis of the isomeric state of the azo group linking two cyclic peptides (Steinem et al., 1999; Vollmer et al., 1999).

\subsubsection{Photobiological Experiments}

The molecular conformation change of the azo chromophore can be used to switch the conformation and hence properties of larger molecular systems to which it is attached. This is particularly interesting in the case of inclusion within molecular-scale biological systems. The bridging of biology and physical 
chemistry is an ever-expanding research domain. It is no surprise that the clean and unique azo photochemistry has been applied to switching biological systems (Willner and Rubin, 1996). One of the earliest investigations of azobenzene in a biological context involved embedding azobenzene molecules into a model membrane system (Balasubramanian et al., 1975). On isomerization, the lamellae were disrupted and rearranged, which also changed the enzymatic activity of membrane-bound proteins. The catalytic activity of a cyclodextrin with a histidine and azobenzene pendant was photocontrollable because the trans version of the azo pendant can bind inside the cyclodextrin pocket, whereas the cis version liberated the catalytic site (Lee and Ueno, 2001). Photoregulation of polypeptide structure has been an active area of research (Ciardelli and Pieroni, 2001), with the azobenzenes making significant contributions. Azo-modified poly (L-alanine) (Sisido et al., 1991a,b), poly(L-glutamic acid) (Houben et al., 1983; Pieroni et al., 1980), and poly(L-lysine) (Malcolm and Pieroni, 1990), among others, have been prepared. Depending on the system, photoisomerization may cause no change (Houben et al., 1983) or can induce a substantial conformational change, including transitions from ordered chiral helix to disordered achiral chain (Fissi et al., 1996; Yamamoto and Nishida, 1991; Montagnoli et al., 1983), changes in the $\alpha$-helix content, or even reversible $\alpha$-helix to $\beta$-sheet conversions (Fissi et al., 1987). Also, owing to the change in local electrostatic environment, the $\mathrm{p} K_{\mathrm{a}}$ of the polypeptides can be controlled in these systems.

Covalent attachment of azobenzene units to enzymes can modify protein activity by distorting the protein structure with isomerization. This was used to control the enzyme activity of papain (Willner and Rubin, 1993; Willner et al., 1991a) and the catalytic efficiency of lysozyme (Inada et al., 2005). A different methodology is to immobilize the protein of interest inside a photoisomerizable copolymer matrix, which was used to control $\alpha$-chymotrypsin (Willner and Rubin, 1993; Willner et al., 1991b, 1993). The azobenzene need not be directly incorporated into an enzyme of interest. In one case, the activity of tyrosinase could be modified by isomerization of small-molecule azo inhibitors (Komori et al., 2004). The photoselective binding of short peptide fragments into enzymes can be used to inhibit, thus control, activity (Harvey and Abell, 2000, 2001). Similarly, the binding of an azopeptide with a monoclonal antibody was found to be photoreversible (Harada et al., 1991). The photoresponse of azobenzene can thus be used to control the availability of key biomolecules. In one case, $\mathrm{NAD}^{+}$was modified with an azobenzene group, and introduced into a mixture with an antibody that binds to the trans form (Hohsaka et al., 1994). This binding makes $\mathrm{NAD}^{+}$unavailable, whereas irradiation of the solution with UV light induces the trans to cis isomerization, and thereby liberates $\mathrm{NAD}^{+}$.

Bioengineering has more recently been broadened by expanding the natural protein alphabet with artificial amino acids. This enables novel and nonnatural protein sequences to be created, while still exploiting the highly efficient natural synthesis machinery. Chiral azobenzene amino acids have been synthesized and incorporated into protein sequences (Wang and Schultz, 2004). The introduction of artificial photoactive residues opens the possibility of 
photocontrol of biological processes. For instance, Escherichia coli variants were selectively evolved that would incorporate azobenzene amino acids into proteins, which enabled photocontrol of protein binding in that organism (Bose et al., 2006). For instance, photocontrol of the binding affinity of a transcription factor to its promoter, allowed for, in essence, light control of gene expression in the organism. In another case, a (negatively charged) hydrophilic azobenzene amino acid was incorporated into a restriction enzyme, and enabled control of activity with light (Nakayama et al., 2004, 2005). Specifically, the trans-azo residue was positioned at the dimer interface, and disrupted association, whereas in the cis state, the proteins could aggregate and exhibit normal biological activity. It has also been suggested that the rapid switching of azobenzene could be used as a "molecular shuttle" for electron transduction in enzyme systems (Voinova and Jonson, 2004). In effect, this would mean that light could be efficiently used to alter behavior in yet another class of enzymes. Incorporation of azobenzene into DNA is another interesting way to control biological systems. In one case, the duplex of modified DNA could be reversibly switched (Asanuma et al., 2001), since the trans-azobenzene intercalates between base pairs and helps bind the two strands of the double helix together, whereas the cis-azobenzene disrupted the duplex (Liang et al., 2003). By incorporating an azobenzene unit into the promoter region of an otherwise normal DNA sequence, it was possible to photocontrol gene expression (Liu et al., 2005). In this case, the trans versus cis states of the azo unit have different interactions with the polymerase enzyme.

These experiments suggest an overall strategy to control biological systems using light. A complex biochemical pathway can be controlled by photoregulating the activity or availability of a key biomolecule. This allows one to turn a biological process on and off at will using light. The use inside living organisms is obviously more complicated, but one can reasonably easily apply these principles to control biological processes in industrially relevant settings. The ability to quickly and cleanly switch biological activity using a short light pulse may find application in new microfluidic devices, which need to be able to address specific device regions and may rely on natural molecular machinery to carry out certain tasks. Azobenzenes present unique opportunities in the biological sciences for studying complex biological systems, in addition to controlling them. A bacteriorhodopsin analog with a central azobenzene molecule, rather than the retinal, was prepared as a model system for studying rhodopsin (Singh et al., 1996). As expected, the azobenzene molecule did not interact as favorably with the protein host as strongly as the natural retinal. Despite this, the azo molecules could be coupled into the protein (in the absence of retinal) and led to significant shifts in the physicochemical properties of the complex. Moreover, the azo molecule could be used as a probe of the inner protein domain (sensing $\mathrm{pH}$, for instance). A particularly elegant experiment involved using azobenzenes to monitor protein folding (Bredenbeck et al., 2003; Spörlein et al., 2002). Femtosecond two-dimensional infrared (2-D IR) spectroscopy was used as a gauge of the distances between carbonyl groups in the peptide. An azobenzene chromophore, incorporated inside the polypeptide chain, acted as the photoswitch, initiating a conformational change, hence initiating protein folding, on 
demand. Simultaneous time-resolved measurements of the azo spectra allowed determination of the folding dynamics. This unique measurement of protein-folding behavior was possible because of the phototriggering nature of the azo unit. Ultrafast laser pulse experiments are used to study a large number of chemical reactions, providing detail not possible before. This technique is, however, obviously limited to systems where the chemical events can be phototriggered. By incorporating azobenzene units into new systems, one can generate a phototriggerable system from an otherwise photoinactive one. This strategy can thus be applied to a wide range of problems in chemical dynamics, with biological systems being obvious targets.

\subsubsection{Photoorientation}

Azobenzene chromophores can be oriented using polarized light ( $\mathrm{Yu}$ and Ikeda, 2004; Ichimura, 2000) via a statistical selection process, described schematically in Fig. 1.9. Azobenzenes preferentially absorb light polarized along their transition dipole axis (long axis of the azomolecule). The probability of absorption varies as $\cos ^{2} \phi$, where $\phi$ is the angle between the light polarization and the azo dipole axis.

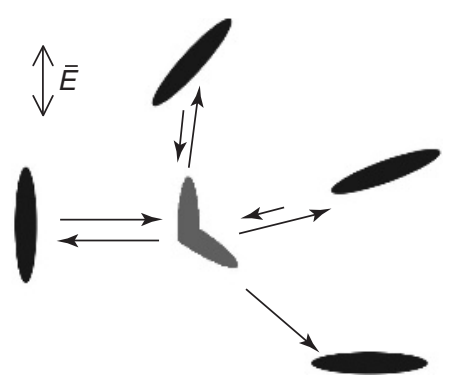

(a)

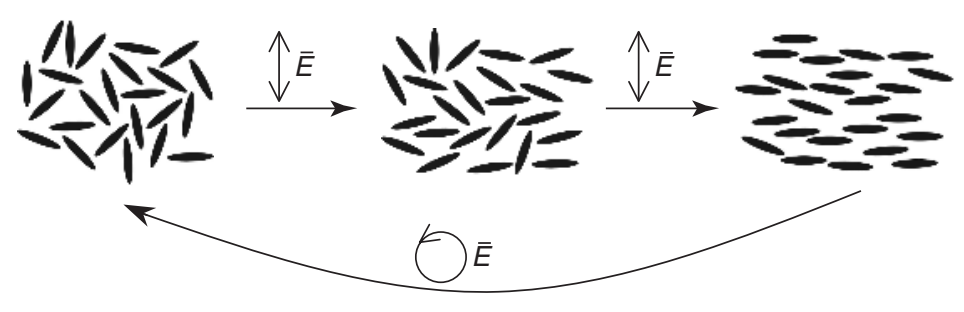

(b)

Figure 1.9. Statistical photoorientation of azomolecules. (a) The molecules aligned along the polarization direction of the incident light absorb, isomerize, and reorient. Those aligned perpendicular cannot absorb and remain fixed. (b) Irradiation of an isotropic samples leads to accumulation of chromophores in the perpendicular direction. Circularly polarized light restores isotropy. 
Thus, azos oriented along the polarization of the light will absorb, whereas those oriented against the light polarization will not. For a given initial angular distribution of chromophores, many will absorb, convert into the cis form and then revert to the trans form with a new random direction. Those chromophores that fall perpendicular to the light polarization will no longer isomerize and reorient; hence, there is a net depletion of chromophores aligned with the light polarization, with a concomitant increase in the population of chromophores aligned perpendicular (i.e., orientation hole burning). This statistical reorientation is fast and gives rise to strong birefringence (anisotropy in refractive index) and dichroism (anisotropy in absorption spectrum) because of the large anisotropy of the azo electronic system. The process is especially efficient because of the mesogenlike cooperative motion that the azobenzene groups facilitate even in amorphous samples below $T_{\mathrm{g}}$ (Wiesner et al., 1991). Since the process requires cycling of the chromophores between the trans and cis states, the pseudo-stilbenes have the fastest response.

The orientation due to polarized light is reversible. The direction can be modified by using a new polarization angle for the irradiating light. Circularly polarized light will randomize the chromophore orientations. It must be emphasized, however, that there is another preferential alignment direction during irradiation: along the axis of the incoming light. It is unavoidable that chromophores will efficiently build up aligned along the irradiation axis, but this is often ignored in the literature, or characterized as "photobleaching" when in fact it is a reversible photoalignment (albeit one that reduces the absorbance as viewed by any photoprobe). Because unpolarized light can photoorient (along the axis of illumination) (Han and Ichimura, 2001), even sunlight is suitable. The motion of the sun through the sky over the course of a day can cause orientation at different tilt angles (Ichimura and Han, 2000). This causes chromophores at different depths to be oriented in different directions, which produces a net chiral helical ordering in the film of a particular handedness (on the basis of the hemisphere in which the experiment is performed). The implications of such results to the origin of absolute chirality in biological systems are intriguing.

1.2.3.1. Birefringence. Irradiation with light polarized in the $\gamma$-direction will lead to net alignment of chromophores in the $x$-direction. As a result, the refractive index probed in the $x$-direction, $n_{x}$, will measure the azo long axis, and will be larger than $n_{y}$. Birefringence is the anisotropy in refractive index: $\Delta n=n_{x}-n_{y}$. Photoalignment in azobenzene systems can achieve extremely high values of $\Delta n$, up to $0.3-0.5$ at $\sim 633 \mathrm{~nm}$ (Hagen and Bieringer, 2001; Natansohn et al., 1994). Importantly, very high birefringence values can be obtained far outside of the azo-absorption band, which means that the birefringence can be utilized/ measured without disturbing the chromophores. An in-plane isotropic state $\left(n_{x}=n_{y}\right)$ can be restored by irradiation with circularly polarized light, and a fully isotropic state can be obtained by heating above the $T_{\mathrm{g}}$.

The exact nature of the orientation can be rigorously quantified using optical techniques. Using surface plasmon resonance spectroscopy or waveguide 
spectroscopy, the three orthogonal refractive indices in an oriented sample can be measured (Tawa and Knoll, 2002). Stokes polarimetry can be used to fully characterize the optical anisotropy, separating linear and circular components (Hore et al., 2002). The anisotropy of the cis population during irradiation can also be measured in some systems (Buffeteau et al., 2001; Sekkat et al., 1995b), where it is found that, as with trans, there is an enrichment perpendicular to the irradiation polarization. In some LC systems, however, it may occur that the cis population preferentially aligns with the irradiating polarization (which may be attributed to an optical Fréedericksz transition) (Hore et al., 2003).

The birefringence can be written and erased hundreds of thousands of times, which is important technologically (Holme et al., 1996). Amorphous polymer systems with relatively high $T_{\mathrm{g}}$ exhibit good temporal stability of any induced orientation. Upon heating, some order will be lost, with full isotropy restored after heating past $T_{\mathrm{g}}$. A short spacer between the chromophore and the polymer backbone slows the growth of birefringence yet promotes stability, owing to hindered motion. Surprisingly, main-chain azos can achieve high levels of birefringence, indicating relatively high polymer mobility ( $\mathrm{Wu}$ et al., 2001b; $\mathrm{Xu}$ et al., 2000; Lee et al., 1998). As might be expected, (nanosecond) pulsed experiments lead to thermal effects, which enhance chromophore motion and thereby induced greater birefringence at the same net dose compared with continuous-wave (cw) experiments (Cimrová et al., 2002; Hildebrandt et al., 1998). At very high pulsed fluence, the thermal effects were too great and erased the induced birefringence.

The easily inscribed and erased birefringence has a number of unique applications. Most readily, it can be used to create wave plates (Shi et al., 1991a) and polarization filters, which can be used to separate right-handed from left-handed circularly polarized light (Natansohn and Rochon, 1999). The strong refractive index contrast, if patterned into a line, can serve as a channel waveguide (Watanabe et al., 1996; Shi et al., 1991b). This offers the unique possibility of optical devices that can be patterned, erased, and reused. In principle, these photonic circuits could be altered during device operation, enabling optical routing of optical signals (i.e., optical computing). The switching of orientational order can thus be used as an all-optical switch (Shishido et al., 1997). By illuminating an azo sample with a spatially varying light pattern, birefringence gratings can also be formed (Eichler et al., 2001; Nikolova et al., 1996; Couture and Lessard, 1988). These are phase gratings, as opposed to amplitude gratings, and diffract light on the basis of spatial variation of the refractive index. This is the essence of holography: two interfering coherent beams generate a spatially varying light pattern, which is encoded into the material. Under illumination of the material with one of the beams, the diffraction reproduces the other encoded beam. In the case of liquid crystal samples, light induces a spatial pattern of nematic and isotropic zones (which have different refractive indices). These holographic phase grating can be rapidly formed, erased, and switched (Yamamoto et al., 2001). 
1.2.3.2. Nonlinear Optics. The requirement for NLO response in any material is an asymmetric (strictly, anharmonic) response of the electronic system. Pseudo-stilbenes, which have push-pull substituents, have a strongly asymmetric electron distribution, which makes them ideal NLO molecules (see, for instance, Fig. 1.10). For a bulk NLO response, one requires an overall noncentrosymmetric material. This requirement is achieved in many inorganic crystals. In organic systems, the broken symmetry is typically obtained by applying an electric field at a temperature sufficient to allow for the molecular dipoles to align with the field. This process is called electric field poling and is accomplished using interdigitated or flat electrodes or a sharp charged needle (or grid) held above a grounded sample (called corona poling). The NLO response is typically quantified using secondharmonic generation (SHG; the emission of light at double the frequency of the incident beam), the electrooptic effect (change of refractive index on application of an electric field), or wave-mixing experiments (where various frequencies of light can be synthesized or enhanced). These also constitute the main applications of NLO materials: they can be used to synthesize new frequencies of light, to electrically switch a beam, or to allow two beams of light to interact and couple (which can form the basis of an all-optical switch) (Eaton, 1991).

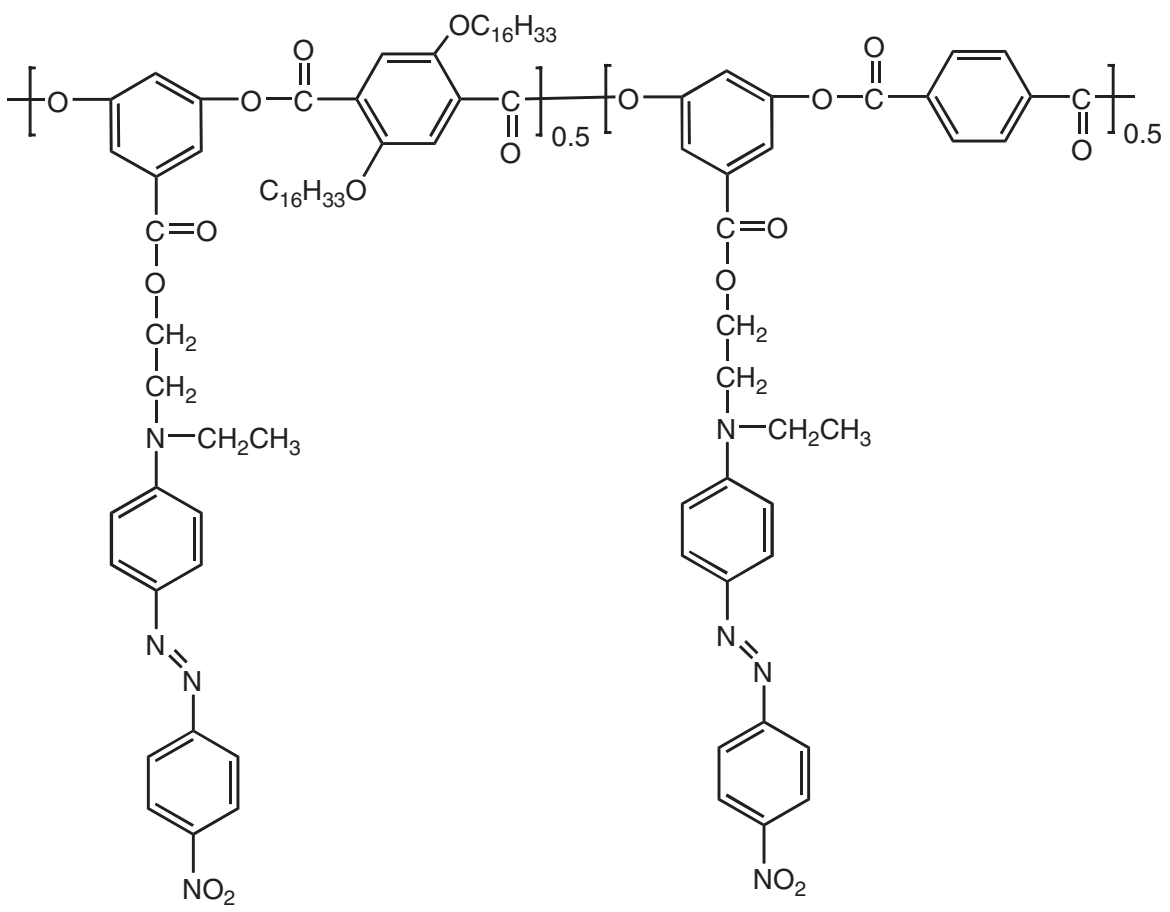

Figure 1.10. Example of a nonlinear optic azo polymer used for photoassisted poling. 
Azo polymers have been shown to be excellent NLO materials (Yesodha et al., 2004; Delaire and Nakatani, 2000; Dalton et al., 1995; Burland et al., 1994). In azo systems, one has the additional advantage of using light to affect the chromophores. Although photoalignment orients the chromophore axis, it does not select out a preferred direction for the molecular dipole (thus, an equal number of dipoles point "left" and "right"). In fact, evidence suggests that dipoles in these systems tend to orient antiparallel (H-aggregates) (Meng et al., 1996; Brown et al., 1995), thereby canceling polar order. Nevertheless, the photoalignment can be used to facilitate the electric poling, enabling it to be performed at room temperature and with a small DC field (Jiang et al., 1996; Sekkat et al., 1995a; Blanchard and Mitchell, 1993a,b). Furthermore, by using polarized light and its harmonic, a net noncentrosymmetry can be obtained in an all-optical process (Zhong et al., 2001; Nunzi et al., 1998). This occurs because the mixture of a primary beam and its second harmonic creates a directional electric field in the material.

Another interesting approach for NLO uses dendrons ("half-dendrimers") with azo functionalities (Yokoyama et al., 2000). The dendritic architecture forces all the chromophores within the dendron to align, which strongly enhances the NLO response. The dendron had a first-order molecular hyperpolarizability 20 times larger than the monomer. With regard to applications, the azos have been shown to function as electro-optical switches (Yamane et al., 1999) and exhibit photorefraction (Iftime et al., 2002; Steenwinckel et al., 2001; Barrett et al., 1998; Ho et al., 1996), an NLO effect where photoconductivity permits light to establish a space charge grating, whose associated index grating refracts a probe light beam.

\subsubsection{Domain Motion}

The orientation and reorientation of LC domains has already been outlined. The azo chromophores act as mesogens and their photoalignment becomes transferred to the LC host. A very small azo content (a few mol\% [Ikeda et al., 1990]) can lead to orientational control of LC domains. This is an excellent example of amplification of the azomolecular motion. The phase of a liquid crystal can also be switched with light. Irradiation produces cis isomers, which are poor mesogens and destabilize the nematic phase, thereby inducing a phase transition to the isotropic state. There are comparatively few examples of phototriggered increases in LC ordering. In one case, a nanoscale phase separation of the cis isomers led to a net increase in the order parameter of the LC phase (Prasad and Nair, 2001). In another system, a chiral azo was found to induce a cholesteric phase when it was in the cis state (Ruslim and Ichimura, 2001).

With LC (Nikolova et al., 1997) or preoriented amorphous samples (Ivanov et al., 2000), one can photoinduce a chiral domain structure. Incident circularly polarized light becomes elliptically polarized because of the first oriented layer. This ellipse subsequently reorients deeper chromophores, which in turn modify the ellipticity of the light. This reorientation continues throughout the film depth. Overall, a chiral ordering of the chromophore domains is established (Nikolova et al., 2000). Remarkably, one can switch between a right- and left-handed 
supramolecular helix at will, by changing the incident light handedness. There are many other examples of photocontrol of supramolecular order. The pitch of a cholesteric LC can be modified by isomerization (Sackmann, 1971). Biomacromolecular variants abound (Willner and Rubin, 1996). Azo-modified polypeptides can be photoswitched between ordered states ( $\alpha$-helix or $\beta$-sheet) and a random coil (Everlof and Jaycox, 2000; Fissi et al., 1996; Yamamoto and Nishida, 1991). The duplex of modified DNA can be reversibly switched (Asanuma et al., 2001), and the catalytic activity of histidine can be controlled (Lee and Ueno, 2001).

Photoisomerization can also affect self-assembly behavior at the domain level. On irradiation, one can induce a phase change (Aoki et al., 2000), a solubility change (Arai and Kawabata, 1995; Yamamoto et al., 1990), crystallization (Ebralidze and Mumladze, 1990), or even reversal of phase separation (Effing and Kwak, 1995). The critical micelle concentration (cmc) and surface activity can also be modified (Yang et al., 1995). In an amphiphilic polypeptide system, selfassembled micelles were formed in the dark and could be disaggregated with light (Higuchi et al., 1994). When allowed to assemble as a transmembrane structure, the aggregate could be reversibly formed and destroyed using light, which allowed for reversible photoswitching of ion transport (Higuchi et al., 1995a). Related experiments on methacrylates (Chen et al., 1997a; Angiolini et al., 1995) and polypeptides (Sisido et al., 1991b) showed that a polymer's chiral helix could be reversibly suppressed on irradiation. In a series of polyisocyanate polymers, it could be selected whether irradiation would suppress or increase chirality (Müller and Zentel, 1996; Maxein and Zentel, 1995).

\subsubsection{Macroscopic Motion}

It is interesting to study whether the azobenzene molecular conformational rearrangements can result in changes to bulk phenomena, or even to macroscopic motion. The first consideration is whether the material expands to an appreciable extent. In monolayers, it is well established that the larger molecular size of the cis isomer leads to a corresponding lateral expansion (Higuchi et al., 1995b), which can modify other bulk properties. For instance, this allows photomodulation of a monolayer's water contact angle (Siewierski et al., 1996) or surface potential (Stiller et al., 1999). Using fluorinated azo polymer, good photocontrol (Feng et al., 2001) and photopatterning (Moller et al., 1998) of wettability has been demonstrated. A monolayer of azo-modified calixarene, when irradiated with a light gradient, produced a gradient in surface energy sufficient to move a macroscopic oil droplet (Ichimura et al., 2000), suggesting possible applications in microfluidics. Modest photoinduced contact angle changes for thin polymer films have also been reported (Sarkar et al., 2001). Recently an azobenzene copolymer assembled into polyelectrolyte multilayer showed a modest $2^{\circ}$ change in contact angle with UV light irradiation. However, when the same copolymer was assembled onto a patterned substrate, the change in contact angle upon irradiation was enhanced to $70^{\circ}$ (Jiang et al., 2005). It is well established that 
surface roughness plays a role in contact angle and many systems can be optimized to give rise to a large change in surface properties.

In layered inorganic systems with intercalated azobenzenes, reversible photochanges in the basal spacing (on the order of 4\%) can be achieved (Fujita et al., 1998, 2001). In polymer films, there is some evidence that the film thickness increases, as measured by ellipsometry (Shi et al., 1991b) (the refractive index certainly changes [Ivanov et al., 1995], but this is not an unambiguous demonstration of expansion-contraction). Experiments that show that external applied pressure tends to hinder photoisomerization (Kleideiter et al., 2000) are related. Photocontraction for semicrystalline main-chain azos has been measured (Eisenbach, 1980b; Agolini and Gay, 1970). This photomechanical response presumably occurs because of the shortening of the polymer chains upon trans $\rightarrow$ cis conversion. However, photoexpansion would seem to be contradicted by positron lifetime experiments that suggest no change in microscopic free volume cavity size during irradiation (Algers et al., 2004). More conclusive experiments are in order.

The most convincing demonstration of macroscopic motion due to azo isomerization is the mechanical bending and unbending of a free-standing polymer film (Ikeda et al., 2003; Yu et al., 2003). The macroscopic bending direction may be selected either with polarized light or by aligning the chromophores with rubbing. Bending occurs in these relatively thick films because the free surface (which absorbs light) contracts, whereas the interior of the film (which is not irradiated owing to the strong absorption of the upper part of the film) does not contract. Because the direction of bending can be controlled with polarized light, the materials enable full directional photomechanical control ( $\mathrm{Yu}$ et al., 2005). This photomechanical deformation has also been used to drive macroscopic motion of a floating film (Camacho-Lopez et al., 2004). That these materials contract (rather than expand) appears again to be related to the main-chain azo groups and may also be related to the LC nature of the cross-linked gels. For a thin film floating on a water surface, a contraction in the direction of polarized light was seen for LC materials, whereas an expansion was seen for amorphous materials (Bublitz et al., 2000). A related amplification of azo motion to macroscopic motion is the photoinduced bending of a microcantilever coated with an azobenzene monolayer (Ji et al., 2004). One can also invert the coupling of mechanical and optical effects: by stretching an elastomeric azo film containing a grating, one can affect its wavelength-selection properties and orient chromophores (Bai and Zhao, 2001).

\subsubsection{Other Applications of Azobenzenes}

1.2.6.1. Photoswitches. As already pointed out, the azo isomerization can be used to photoswitch a wide variety of other properties (at numerous size scales). In addition to the optical changes already described, it is worth noting that the transient change in material refractive index (owing to the different $n$ of cis and trans) can itself act as a photoswitch (Barley et al., 1991). The azo photochromism 
has even been suggested as a possible optical neural network element (Sumaru et al., 1999). Binding and transport properties can also be photoswitched (Weh et al., 1998; Anzai and Osa, 1994). In some systems the redox potential and ionic conductivity can be switched with light (Willner and Willner, 1997). Crown ethers (Zawisza et al., 1999; Tokuhisa et al., 1994) and calixarenes (Reynier et al., 1998) functionalized with azobenzene can be used as reversible ion-binding systems. Thus, ion transport can be photoregulated. In other cases, the transport properties can be photocontrolled not via binding but on the basis of changes in pore sizes (Sata et al., 2000; Abraham and Purushothaman, 1998; Kano et al., 1980). In a particularly elegant example, the size of nanochannels could be modified by irradiating azo ligands that decorate the channel walls (Liu et al., 2004). Azoderivatized gramicidin ion channels represent a unique case where ion transport can be photocontrolled by the optical manipulation of a biomolecule (Lien et al., 1996). In addition to obvious applications in controlled transport, this offers the possibility of studying cells by controlling the timing of ion exchange processes. Photoinduced catalysis is also possible, for instance, using molecules where only the cis form is catalytically active (Wuerthner and Rebek, 1995). Extension of the molecular imprinting technique to azo polymers allows for photoswitching of binding activity with respect to the imprinted molecule (Minoura et al., 2004).

1.2.6.2. Photoprobes. The properties of an azo chromophore (spectrum, isomerization kinetics, etc.) depend strongly on the local environment. This enables the possibility of using the chromophore as a molecular sensing element: a photoprobe. For instance, it has been found that many azo properties depend on local $\mathrm{H}^{+}$concentration, to the extent that the azo can in fact be used as a $\mathrm{pH}$ meter (Uznanski and Pecherz, 2002; Mermut and Barrett, 2001). As mentioned earlier, the isomerization kinetics can also be used as a probe of free volume (Naito et al., 1993; Lamarre and Sung, 1983), local aggregation (Norman and Barrett, 2002), or phase transitions. The azo molecule is small and exhibits clean photochemistry, which makes it more versatile and robust than many other photoprobes. The rate of isomerization is also remarkably insensitive to temperature (Yamamoto, 1986), yet sensitive to local solvent conditions ( $\mathrm{Li}$ et al., 2006; Norman and Barrett, 2002). This is an area of research that deserves considerably more attention.

In a more sophisticated example, azo chromophores were used to monitor protein folding (Bredenbeck et al., 2003; Spörlein et al., 2002). Specifically, femtosecond 2-D IR spectroscopy was used to monitor the distances between carbonyl groups in the peptide. An azo chromophore, incorporated inside the polypeptide chain, was used as a photoswitch to initiate a conformational change, hence initiate protein folding, on demand. Combined with time-resolved monitoring of the azo spectrum, this allows the deconvolution of folding dynamics. Pumpprobe ultrafast laser pulse experiments are being used to study many different chemical reactions, but are obviously limited to reactions that can be triggered by light. Incorporating azobenzene into the experiment allows a wider range of reactions to be phototriggered. 
1.2.6.3. Optical Data Storage. The azos have been investigated as optical storage media for some time. Early proofs of principle were on LangmuirBlodgett films, using photochromism (Liu et al., 1990) or birefringence (Dhanabalan et al., 1999). Increasingly, amorphous polymer systems are being recognized as promising materials. In these easily processed systems, the birefringence is strong, stable, and switchable, making them ideal for optical memories. A single domain could encode one bit by either being isotropic or birefringent, a difference that is easily probed optically. The $\Delta n$ values are large enough, in fact, that a gray-level algorithm could be used, where each domain stores more than one bit of data. On the negative side, the photoalignment generated in the direction of the read-write beam leads to an effective loss of material performance with time. Full anisotropy could be restored with heat, however (which can be local and photoinduced, with appropriate device setup). The feasibility of storing $~ 30 \mathrm{~GB}$ of data on a single layer of a removable disk using this gray-level approach has been demonstrated (Hagen and Bieringer, 2001).

Even the fastest photoinduced birefringence in azo systems requires milliseconds and is slow compared with most computer timescales. However, optical data storage is amenable to gray-level read-write (Sabi et al., 2001) and to storingretrieving full 2-D "pages" of data at a time. In principle, azo systems could achieve high data storage and retrieval speeds. The full 3-D volume of a material can be used by encoding many layers of 2-D data (pages) one on top of the other (Kawata and Kawata, 2000; Ishikawa et al., 1998). This is accomplished by moving the optical focal plane through the material.

An intriguing possibility for high density storage is to use angular multiplexing (Hagen and Bieringer, 2001). By storing multiple superimposed holograms in a single material, the data density is increased dramatically, and the whole 3-D volume of the material is exploited (Ramanujam et al., 2001). Volume-phase holograms in azo systems can have diffraction efficiencies greater than 90\% (Zilker et al., 1998), making data readout robust. The hologram is encoded by interfering a reference beam and a writing beam inside the sample volume, at a particular angle. The write beam, having passed through a spatial light modulator (SLM), has a pattern corresponding to the data, which is then holographically encoded in the sample. The entire page of data is written at once. By selecting different angles, new pages of data can be written. To readout a page, the azo sample is set at the correct angle and illuminated with the reference beam. The resulting diffraction pattern is imaged on a charge-coupled device (CCD) array, which measures the encoded beam pattern (data). The volume of data and transmission rate is clearly large: projections of $\sim 1000 \mathrm{~GB}$ in a single disk have been made. Since the entire hologram image is stored throughout the material, the technique is fairly insensitive to dust, scratches, and pinpoint defects.

The use of azo-substituted peptide oligomers appears to enable control of the order, hence optimization for holographic applications (Berg et al., 1996). Optical memories would be considerably enhanced by using two-photon processes. This allows the addressable volume to be smaller and better defined, while reducing 
cross-talk between encoded pages. Some azo chromophores exhibit "biphotonic" phenomena, which could be employed to enhance optical data storage.

1.2.6.4. Surface Mass Transport. In 1995, a surprising and unprecedented optical effect was discovered in polymer thin films containing the azo chromophore Disperse Red 1 (DR1). The Natansohn-Rochon (Rochon et al., 1995) research team and the Tripathy-Kumar collaboration (Kim et al., 1995) simultaneously and independently discovered a large-scale surface mass transport when the films were irradiated with a light interference pattern. In a typical experiment, two coherent laser beams, with a wavelength in the azo-absorption band, are intersected at the sample surface. The sample usually consists of a thin spin-cast film $(10-1000 \mathrm{~nm})$ of an amorphous azo polymer on a transparent substrate. The sinusoidal light interference pattern at the sample surface leads to a sinusoidal surface patterning, that is, a surface relief grating (SRG). These gratings were found to be extremely large, up to hundreds of nanometers, as confirmed by atomic force microscopy (AFM). The SRGs diffract very efficiently, and in retrospect, it is clear that many reports of large diffraction efficiency before 1995, attributed to birefringence, were in fact due to surface gratings. The process occurs readily at room temperature (well below the $T_{\mathrm{g}}$ of the amorphous polymers used) with moderate irradiation $\left(1-100 \mathrm{~mW} \mathrm{~cm}^{-2}\right)$ over seconds to minutes. The phenomenon is a reversible mass transport, not irreversible material ablation, since a flat film with the original thickness is recovered upon heating above $T_{\mathrm{g}}$. Critically, it requires the presence and isomerization of azobenzene chromophores. Other absorbing but nonisomerizing chromophores do not produce SRGs. Many other systems can exhibit optical surface patterning (Yamaki et al., 2000), but the amplitude of the modification is much smaller, does not involve mass transport, and usually requires additional processing steps. The all-optical patterning unique to azobenzenes has been studied intensively since its discovery, yet there remains controversy regarding the mechanism. The competing interpretations are evaluated in Chapter 4, where they are discussed at length. Many reviews of the remarkable body of experimental results are available (Natansohn and Rochon, 2002; Delaire and Nakatani, 2000; Yager and Barrett, 2001; Viswanathan et al., 1999).

\section{ACKNOWLEDGMENT}

This work is dedicated to Professors Almeria Natansohn and Sukant Tripathy, teachers and pioneers in the field of azo polymers, who were unable to see the completion of this book.

\section{REFERENCES}

Abraham G, Purushothaman E. 1998. Synthesis and photostimulated dilation changes of polymers with azobenzene cross-links. Indian J Chem Technol 5(4):213-216. 
Advincula R, Park M-K, Baba A, Kaneko F. 2003. Photoalignment in ultrathin films of a layer-by-layer deposited water-soluble azobenzene dye. Langmuir, 19(3):654-665.

Advincula RC. 2002. Polyelectrolyte layer-by-layer self-assembled multilayers containing azobenzene dyes. In: Tripathy SK, Kumar J, Nalwa HS, editors. Handbook of Polyelectrolytes and Their Applications. Stevenson Ranch (CA): American Scientific Publishers, p. 65-97.

Advincula RC, Fells E, Park M-K. 2001. Molecularly ordered low molecular weight azobenzene dyes and polycation alternate multilayer films: aggregation, layer order, and photoalignment. Chem Mater 13(9):2870-2878.

Agolini F, Gay FP. 1970. Synthesis and properties of azoaromatic polymers. Macromolecules 3(3):349-351.

Aida T, Jiang D-L, Yashima E, Okamoto Y. 1998. A new approach to light-harvesting with dendritic antenna. Thin Solid Films 331(1-2):254-258.

Algers J, Sperr P, Egger W, Liszkay L, Kogel G, Baerdemaeker J, Maurer FHJ. 2004. Free volume determination of azobenzene-PMMA copolymer by a pulsed low-energy positron lifetime beam with in-situ UV illumination. Macromolecules 37(21):8035-8042.

Altomare A, et al. 2001. Synthesis and polymerization of amphiphilic methacrylates containing permanent dipole azobenzene chromophores. J Polym Sci, Part A 39(17):2957-2977.

Altomare A, Ciardelli F, Tirelli N, Solaro R. 1997. 4-Vinylazobenzene: polymerizability and photochromic properties of its polymers. Macromolecules 30(5):1298-1303.

Anderle K, Birenheide R, Eich M, Wendorff JH. 1989. Laser-induced reorientation of the optical axis in liquid-crystalline side chain polymers. Makromol Chem, Rapid Commun 10(9):477-483.

Anderle K, Birenheide R, Werner MJA, Wendorff JH. 1991. Molecular addressing? Studies on light-induced reorientation in liquid-crystalline side chain polymers. Liq Cryst 9(5):691-699.

Angeli C, Cimiraglia R, Hofmann H-J. 1996. On the competition between the inversion and rotation mechanisms in the cis-trans thermal isomerization of diazene. Chem Phys Lett 259(3-4):276-282.

Angiolini L, Caretti D, Carlini C, Salatelli E. 1995. Optically active polymers bearing sidechain photochromic moieties: synthesis and chiroptical properties of methacrylic and acrylic homopolymers with pendant L-lactic acid or L-alanine residues connected to trans-4-aminoazobenzene. Macromol Chem Phys 196(9):2737-2750.

Antipov AA, Sukhorukov GB, Möhwald H. 2003. Influence of the ionic strength on the polyelectrolyte multilayers' permeability. Langmuir 19(6):2444-2448.

Anzai J-I, Osa T. 1994. Photosensitive artificial membranes based on azobenzene and spirobenzopyran derivatives. Tetrahedron 50(14):4039-4070.

Aoki K, Nakagawa M, Ichimura K. 2000. Self-assembly of amphoteric azopyridine carboxylic acids: organized structures and macroscopic organized morphology influenced by heat, pH change, and light. J Am Chem Soc 122(44):10997-11004.

Arai K, Kawabata Y. 1995. Changes in the sol-gel transformation behavior of azobenzene moiety-containing methyl cellulose irradiated with UV light. Macromol Rapid Commun 16(12):875-880.

Asakawa M, et al. 1999. Photoactive azobenzene-containing supramolecular complexes and related interlocked molecular compounds. Chem Eur J 5(3):860-875. 
Asanuma H, Liang X, Yoshida T, Komiyama M. 2001. Photocontrol of DNA duplex formation by using azobenzene-bearing oligonucleotides. ChemBioChem 2(1):39-44.

Bai S, Zhao Y. 2001. Azobenzene-containing thermoplastic elastomers: coupling mechanical and optical effects. Macromolecules 34(26):9032-9038.

Balasubramanian D, Subramani S, Kumar C. 1975. Modification of a model membrane structure by embedded photochrome. Nature 254(5497):252-254.

Balasubramanian S, et al. 1998. Azo chromophore-functionalized polyelectrolytes. 2. Acentric self-assembly through a layer-by-layer deposition process. Chem Mater 10(6):1554-1560.

Balzani V, Credi A, Marchioni F, Stoddart JF. 2001. Artificial molecular-level machines. Dethreading-rethreading of a pseudorotaxane powered exclusively by light energy. Chem Commun 18:1860-1861.

Barley SH, Gilbert A, Mitchell GR. 1991. Photoinduced reversible refractive-index changes in tailored siloxane-based polymers. J Mater Chem 1(3):481-482.

Barrett C, Natansohn A, Rochon P. 1994. Thermal cis-trans isomerization rates of azobenzenes bound in the side chain of some copolymers and blends. Macromolecules 27(17):4781-4786.

Barrett C, Natansohn A, Rochon P. 1995. Cis-trans thermal isomerization rates of bound and doped azobenzenes in a series of polymers. Chem Mater 7(5):899-903.

Barrett C, Choudhury B, Natansohn A, Rochon P. 1998. Azocarbazole polymethacrylates as single-component electrooptic materials. Macromolecules 31(15):4845-4851.

Beltrame PL, et al. 1993. Thermal cis-trans-isomerization of azo dyes in poly(methyl methacrylate) matrix - a kinetic-study. J Appl Polym Sci 49(12):2235-2239.

Berg RH, Hvilsted S, Ramanujam PS. 1996. Peptide oligomers for holographic data storage. Nature 383:505-508.

Bian S, He J-A, Li L, Kumar J, Tripathy SK. 2000. Large photoinduced birefringence in Azo dye/polyion films assembled by electrostatic sequential adsorption. Adv Mater 12(16):1202-1205.

Bignozzi MC, et al. 1999. Liquid crystal poly(glycidyl ether)s by anionic polymerization and polymer-analogous reaction. Polymer J (Tokyo) 31(11-1):913-919.

Birabassov R, et al. 1998. Thick dye-doped poly(methyl methacrylate) films for real-time holography. Appl Opt 37(35):8264-8269.

Blanchard PM, Mitchell GR. 1993a. A comparison of photoinduced poling and thermal poling of azo-dye-doped polymer films for second order nonlinear optical applications. Appl Phys Lett 63(15):2038-2040.

Blanchard PM, Mitchell GR. 1993b. Localized room temperature photo-induced poling of azo-dye-doped polymer films for second-order nonlinear optical phenomena. J Phys D 26(3):500-503.

Blinov LM, Kozlovsky MV, Ozaki M, Skarp K, Yoshino K. 1998. Photoinduced dichroism and optical anisotropy in a liquid-crystalline azobenzene side chain polymer caused by anisotropic angular distribution of trans and cis isomers. J Appl Phys 84(7):3860-3866.

Bortolus P, Monti S. 1979. Cis-trans photoisomerization of azobenzene. Solvent and triplet donors effects. J Phys Chem 83(6):648-652.

Bose M, Groff D, Xie J, Brustad E, Schultz PG. 2006. The incorporation of a photoisomerizable amino acid into proteins in E. coli. J Am Chem Soc 128(2):388-389. 
Bredenbeck J, et al. 2003. Transient 2D-IR spectroscopy: snapshots of the nonequilibrium ensemble during the picosecond conformational transition of a small peptide. J Phys Chem B 107(33):8654-8660.

Brown CJ. 1966. A refinement of the crystal structure of azobenzene. Acta Cryst 21(1): $146-152$.

Brown D, Natansohn A, Rochon P. 1995. Azo polymers for reversible optical storage. 5. Orientation and dipolar interactions of azobenzene side groups in copolymers and blends containing methyl methacrylate structural units. Macromolecules 28(18):6116-6123.

Brown EV, Granneman GR. 1975. Cis-trans isomerism in pyridyl analogs of azobenzenekinetic and molecular-orbital analysis. J Am Chem Soc 97(3):621-627.

Bublitz D, et al. 2000. Photoinduced deformation of azobenzene polyester films. Appl Phys B: Lasers Opt 70(6):863-865.

Buffeteau T, Labarthet FL, Pézolet M, Sourisseau C. 2001. Dynamics of photoinduced orientation of nonpolar azobenzene groups in polymer films. Characterization of the cis isomers by visible and FTIR spectroscopies. Macromolecules 34(21):7514-7521.

Burke SE, Barrett CJ. 2003a. Acid-base equilibria of weak polyelectrolytes in multilayer thin films. Langmuir 19(8):3297-3303.

Burke SE, Barrett CJ. 2003b. pH-Responsive properties of multilayered poly(L-lysine)/ hyaluronic acid surfaces. Biomacromolecules 4(6):1773-1783.

Burland DM, Miller RD, Walsh CA. 1994. Second-order nonlinearity in poled-polymer systems. Chem Rev 94(1):31-75.

Camacho-Lopez M, Finkelmann H, Palffy-Muhoray P, Shelley M. 2004. Fast liquid-crystal elastomer swims into the dark. Nat Mate 3(5):307-310.

Campbell VE, et al. 2006. Chromophore orientation dynamics, phase stability, and photorefractive effects in branched azobenzene chromophores. Macromolecules 39(3):957-961.

Caruso F. 2001. Nanoengineering of particle surfaces. Adv Mater 13(1):11-22.

Caruso F, Möhwald H. 1999. Protein multilayer formation on colloids through a stepwise self-assembly technique. J Am Chem Soc 1212(25):6039-6046.

Chen AG, Brady DJ. 1993. Two-wavelength reversible holograms in azo-dye doped nematic liquid crystals. Appl Phys Lett 62(23):2920-2922.

Chen JP, Gao JP, Wang ZY. 1997a. Preparation and photochemical study of soluble optically active block copolymethacrylates and azo-containing random copolymethacrylates. J Polym Sci, Part A 35(1):9-16.

Chen SH, et al. 1995. Novel glass-forming organic materials. 1. Adamantane with pendant cholesteryl, disperse red 1, and nematogenic groups. Macromolecules 28(23):7775-7778.

Chen SH, Mastrangelo JC, Shi H, Blanton TN, Bashir-Hashemi A. 1997b. Novel glassforming organic materials. 3. Cubane with pendant nematogens, carbazole, and disperse red 1. Macromolecules 30(1):93-97.

Chiarelli PA, et al. 2001. Controlled fabrication of polyelectrolyte multilayer thin films using spin-assembly. Adv Mater 13(15):1167-1171.

Cho J, Char K, Hong J-D, Lee K-B. 2001. Fabrication of highly ordered multilayer films using a spin self-assembly method. Adv Mater 13(14):1076-1078.

Chung AJ, Rubner MF. 2002. Methods of loading and releasing low molecular weight cationic molecules in weak polyelectrolyte multilayer films. Langmuir 18(4):1176-1183. 
Ciardelli F, Pieroni O. 2001. Photoswitchable polypeptides. In: Feringa BL, editor Molecular Switches, Hoboken, NJ: Wiley, p. 399-441.

Cimrová V, et al. 2002. Comparison of the birefringence in an azobenzene-side-chain copolymer induced by pulsed and continuous-wave irradiation. Appl Phys Lett 81(7):1228-1230.

Couture JJA, Lessard RA. 1988. Modulation transfer function measurements for thin layers of azo dyes in PVA matrix used as an optical encoding material. Appl Opt 27(16):3368-3374.

Dalton LR, et al. 1995. Synthesis and processing of improved organic second-order nonlinear optical materials for applications in photonics. Chem Mater 7(6):1060-1081.

Dante S, Advincula RC, Frank CW, Stroeve P. 1999. Photoisomerization of polyionic layer-by-layer films containing azobenzene. Langmuir 15(1):193-201.

de Lange JJ, Robertson JM, Woodward I. 1939. X-ray crystal analysis of trans-azobenzene. Proc Roy Soc (London) A171:398-410.

Decher G. 1997. Fuzzy nanoassemblies: toward layered polymeric multicomposites. Science 277(5330):1232-1237.

Decher G, Hong JD. 1991. Buildup of ultrathin multilayer films by a self-assembly process: II. Consecutive adsorption of anionic and cationic bipolar amphiphiles and polyelectrolytes on charged surfaces. Berichte der Bunsen-Gesellschaft 95(11):1430-1434.

Decher G, Schmitt J. 1992. Fine-tuning of the film thickness of ultrathin multilayer films composed of consecutively alternating layers of anionic and cationic polyelectrolytes. Prog Colloid Polym Sci 89(Trends Colloid Interface Sci VI):160-164.

Decher G, Hong JD, Schmitt J. 1991. Buildup of ultrathin multilayer films by a selfassembly process: III. Consecutively alternating adsorption of anionic and cationic polyelectrolytes on charged surfaces. Thin Solid Films 210-211(Part 2):831-835.

Decher G, Eckle M, Schmitt J, Struth B. 1998. Layer-by-layer assembled multicomposite films. Curr Opin Colloid Interface Sci 3(1):32-39.

Delaire JA, Nakatani K. 2000. Linear and nonlinear optical properties of photochromic molecules and materials. Chem Rev 100(5):1817-1846.

Dhanabalan A, et al. 1999. Optical storage in mixed langmuir-blodgett (LB) films of disperse Red-19 Isophorone polyurethane and cadmium stearate. Langmuir 15(13):4560-4564.

Diaspro A, Silvano D, Krol S, Cavalleri O, Gliozzi A. 2002. Single living cell encapsulation in nano-organized polyelectrolyte shells. Langmuir 18(13):5047-5050.

dos Santos DS Jr., et al. 2003. Light-induced storage in layer-by-layer films of chitosan and an azo dye. Biomacromolecules 4(6):1502-1505.

Dragan S, Schwarz S, Eichhorn K-J, Lunkwitz K. 2003. Electrostatic self-assembled nanoarchitectures between polycations of integral type and azo dyes. Colloids Surf A 195(1-3):243-251.

Dubas ST, Schlenoff JB. 1999. Factors controlling the growth of polyelectrolyte multilayers. Macromolecules 32(24):8153-8160.

Eaton DF. 1991. Nonlinear optical materials. Science 253(5017):281-287.

Ebralidze TD, Mumladze AN. 1990. Light-induced anisotropy in azo-dye-colored materials. Appl Opt 29(4):446-447.

Effing JJ, Kwak JCT. 1995. Photoswitchable phase separation in hydrophobically modified polyacrylamide/surfactant systems. Angew Chem Int Ed Engl 34(1):88-90. 
Eich M, Wendorff J. 1990. Laser-induced gratings and spectroscopy in monodomains of liquid-crystalline polymers. J Opt Soc Am B 7(8):1428.

Eichler HJ, Orlic S, Schulz R, Rübner J. 2001. Holographic reflection gratings in azobenzene polymers. Opt Lett 26(9):581-583.

Eisenbach CD. 1980a. Cis-trans isomerization of aromatic azo chromophores, incorporated in the hard segments of poly(ester urethane)s. Macromol Rapid Commun 1(5):287-292.

Eisenbach CD. 1980b. Isomerization of aromatic azo chromophores in poly(ethyl acrylate) networks and photomechanical effect. Polymer 21(10):1175-1179.

Evans SD, Johnson SR, Ringsdorf H, Williams LM, Wolf H. 1998. Photoswitching of azobenzene derivatives formed on planar and colloidal gold surfaces. Langmuir 14(22):6436-6440.

Everlof GJ, Jaycox GD. 2000. Stimuli-responsive polymers. 4. Photo- and thermoregulated chiroptical behavior in azobenzene-modified polymers fitted with main chain spirobiindane turns and chiral binaphthyl bends. Polymer 41(17):6527-6536.

Feng CL, et al. 2001. Reversible wettability of photoresponsive fluorine-containing azobenzene polymer in langmuir-blodgett films. Langmuir 17(15):4593-4597.

Fischer B, et al. 1997. The packing of azobenzene dye moieties and mesogens in polysiloxane copolymers and its impact on the opto-dielectric effect. Liq Cryst 22(1):65-74.

Fischer E. 1967. Calculation of photostationary states in systems A-B when only A is known. J Phys Chem 71(11):3704-3706.

Fissi A, Pieroni O, Ciardelli F. 1987. Photoresponsive polymers-azobenzene-containing poly(L-lysine). Biopolymers 26(12):1993-2007.

Fissi A, Pieroni O, Balestreri E, Amato C. 1996. Photoresponsive polypeptides. Photomodulation of the macromolecular structure in poly(N((phenylazophenyl)sulfonyl)- L-lysine). Macromolecules 29(13):4680-4685.

Fujino T, Tahara T. 2000. Picosecond time-resolved raman study of trans-azobenzene. J Phys Chem A 104(18):4203-4210.

Fujino T, Arzhantsev SY, Tahara T. 2001. Femtosecond time-resolved fluorescence study of photoisomerization of trans-azobenzene. J Phys Chem A 105(35):8123-8129.

Fujita T, Iyi N, Klapyta Z. 1998. Preparation of azobenzene-mica complex and its photoresponse to ultraviolet irradiation. Mater Res Bull 33(11):1693-1701.

Fujita T, Iyi N, Klapyta Z. 2001. Optimum conditions for photoresponse of azobenzeneorganophilic tetrasilicic mica complexes. Mater Res Bull 36(3-4):557-571.

Funke U, Gruetzmacher HF. 1987. Dithiadiaza[n.2]paracyclophenes. Tetrahedron 43(16):3787-3795.

Furukawa J, Takamori S, Yamashita S. 1967. Preparation of block copolymers with a macro-azo-nitrile as an initiator. Angew Makromol Chem 1(1):92-104.

Gabor G, Fischer E. 1971. Spectra and cis-trans isomerism in highly dipolar derivatives of azobenzene. J Phys Chem 75(4):581-583.

Gallot B, Fafiotte M, Fissi A, Pieroni O. 1996. Liquid-crystalline structure of poly(L-lysine) containing azobenzene units in the side chain. Macromol Rapid Commun 17(8):493-501. 
Gegiou D, Muszkat KA, Fischer E. 1968. Temperature dependence of photoisomerization. V. Effect of substituents on the photoisomerization of stilbenes and azobenzenes. J Am Chem Soc 90(15):3907-3918.

Gibbons WM, Shannon PJ, Sun S-T, Swetlin BJ. 1991. Surface-mediated alignment of nematic liquid crystals with polarized laser light. Nature 351(6321):49-50.

Haberfield P, Block PM, Lux MS. 1975. Enthalpies of solvent transfer of transition-states in cis-trans isomerization of azo-compounds - rotation vs nitrogen inversion mechanism. J Am Chem Soc 97(20):5804-5806.

Hagen R, Bieringer T. 2001. Photoaddressable polymers for optical data storage. Adv Mater 13(23): 1805-1810.

Hair SR, Taylor GA, Schultz LW. 1990. An easily implemented flash-photolysis experiment for the physical-chemistry laboratory - the isomerization of 4-Anilino-4'-Nitroazobenzene. J Chem Educ 67(8):709-712.

Hammond PT. 1999. Recent explorations in electrostatic multilayer thin film assembly. Curr Opin Colloid Interface Sci 4(6):430-442.

Hampson GC, Robertson JM. 1941. Bond length and resonance in the cis-azobenzene molecule. J Chem Soc Abstracts:409-413.

Han M, Ichimura K. 2001. Tilt orientation of p-methoxyazobenzene side chains in liquid crystalline polymer films by irradiation with nonpolarized light. Macromolecules 34(1):82-89.

Harada M, Sisido M, Hirose J, Nakanishi M. 1991. Photoreversible antigen-antibody reactions. FEBS Lett 286(1-2):6-8.

Hartley GS. 1937. Cis form of azobenzene. Nature 140:281.

Hartley GS. 1938. Cis form of azobenzene and the velocity of the thermal cis-trans conversion of azobenzene and some derivatives. J Chem Soc Abstracts:633-642.

Harvey AJ, Abell AD. 2000. Azobenzene-containing, peptidyl a-ketoesters as photobiological switches of a-chymotrypsin. Tetrahedron 56(50):9763-9771.

Harvey AJ, Abell AD. 2001. a-Ketoester-based photobiological switches: synthesis, peptide chain extension and assay against a-chymotrypsin. Bioorg Med Chem Lett 11(18):2441-2444.

Hayashi T, et al. 1995. Photo-induced phase transition of side chain liquid crystalline copolymers with photochromic group. Eur Polym J 31(1):23-28.

He J-A, et al. 2000a. Photochemical behavior and formation of surface relief grating on self-assembled polyion/dye composite film. J Phys Chem B 104(45):10513-10521.

He J-A, et al. 2000b. Surface relief gratings from electrostatically layered azo dye films. Appl Phys Lett 76(22):3233-3235.

Higuchi M, Minoura N, Kinoshita T. 1994. Photocontrol of micellar structure of an azobenzene containing amphiphilic sequential polypeptide. Chem Lett (2):227-230.

Higuchi M, Minoura N, Kinoshita T. 1995a. Photoinduced structural and functional changes of an azobenzene containing amphiphilic sequential polypeptide. Macromolecules 28(14):4981-4985.

Higuchi M, Minoura N, Kinoshita T. 1995b. Photo-responsive behavior of a monolayer composed of an azobenzene containing polypeptide in the main-chain. Colloid Polym Sci 273(11):1022-1027. 
Hildebrandt R, et al. 1998. Time-resolved investigation of photoinduced birefringence in azobenzene side-chain polyester films. Phys Rev Lett 81:5548-5551.

Ho C-H, Yang K-N, Lee S-N. 2001. Mechanistic study of trans-cis isomerization of the substituted azobenzene moiety bound on a liquid-crystalline polymer. J Polym Sci, Part A 39(13):2296-2307.

Ho MS, et al. 1996. Synthesis and optical properties of poly\{(4-nitrophenyl)-[3-[N-[2(methacryloyloxy)ethyl]carbazolyl]]diazene\}. Macromolecules 29(13):4613-4618.

Hohsaka T, Kawashima K, Sisido M. 1994. Photoswitching of Nad+-mediated enzyme reaction through photoreversible antigen-antibody reaction. J Am Chem Soc 116(1):413-414.

Holland NB, et al. 2003. Single molecule force spectroscopy of azobenzene polymers: switching elasticity of single photochromic macromolecules. Macromolecules 36(6):2015-2023.

Holme NCR, Ramanujam PS, Hvilsted S. 1996. 10,000 optical write, read, and erase cycles in an azobenzene sidechain liquid-crystalline polyester. Opt Lett 21(12):902-904.

Hong J-D, Jung B-D, Kim CH, Kim K. 2000. Effects of spacer chain lengths on layered nanostructures assembled with main-chain azobenzene ionenes and polyelectrolytes. Macromolecules 33(21):7905-7911.

Hore DK, Natansohn A, Rochon PL. 2002. Optical anisotropy as a probe of structural order by stokes polarimetry. J Phys Chem B 106(35):9004-9012.

Hore DK, Natansohn AL, Rochon PL. 2003. Anomalous cis isomer orientation in a liquid crystalline azo polymer on irradiation with linearly polarized light. J Phys Chem B 107(10):2197-2204.

Houben JL, et al. 1983. Azobenzene-containing poly(L-glutamates) - photochromism and conformation in solution. Int J Biol Macromol 5(2):94-100.

Hugel T, et al. 2002. Single-molecule optomechanical cycle. Science 296(5570):1103-1106.

Hvilsted S, Andruzzi F, Kulinna C, Siesler HW, Ramanujam PS. 1995. Novel side-chain liquid crystalline polyester architecture for reversible optical storage. Macromolecules 28(7):2172-2183.

Ichimura K. 2000. Photoalignment of liquid-crystal systems. Chem Rev 100(5):1847-1873.

Ichimura K, Han M. 2000. Molecular reorientation induced by sunshine suggesting the generation of absolute chirality. Chem Lett 29(3):286-287.

Ichimura K, Hayashi Y, Akiyama H, Ikeda T, Ishizuki N. 1993. Photo-optical liquid crystal cells driven by molecular rotors. Appl Phys Lett 63(4):449-451.

Ichimura K, Momose M, Kudo K, Akiyama H, Ishizuki N. 1996. Surface-assisted formation of anisotropic dye molecular films. Thin Solid Films 284-285:557-560.

Ichimura K, Oh S-K, Nakagawa M. 2000. Light-driven motion of liquids on a photoresponsive surface. Science 288(5471):1624-1626.

Iftime G, Labarthet FL, Natansohn A, Rochon P, Murti K. 2002. Main chain-containing azotetraphenyldiaminobiphenyl photorefractive polymers. Macromolecules 14(1):168-174.

Ikeda T, Tsutsumi O. 1995. Optical switching and image storage by means of azobenzene liquid-crystal films. Science 268(5219):1873-1875.

Ikeda T, Horiuchi S, Karanjit DB, Kurihara S, Tazuke S. 1990. Photochemically induced isothermal phase transition in polymer liquid crystals with mesogenic phenyl benzoate 
side chains. 2. Photochemically induced isothermal phase transition behaviors. Macromolecules 23(1):42-48.

Ikeda T, Sasaki T, Ichimura K. 1993. Photochemical switching of polarization in ferroelectric liquid-crystal films. Nature 361:428-430.

Ikeda T, Nakano M, Yu Y, Tsutsumi O, Kanazawa A. 2003. Anisotropic bending and unbending behavior of azobenzene liquid-crystalline gels by light exposure. Adv Mater 15(3):201-205.

Inada T, Terabayashi T, Yamaguchi Y, Kato K, Kikuchi K. 2005. Modulation of the catalytic mechanism of hen egg white lysozyme (HEWL) by photochromism of azobenzene. J Photochem Photobiol A 175(2-3):100-107.

Ishikawa J, et al. 2002. Photo-induced in-plane alignment of LC molecules on layer-bylayer self-assembled films containing azo dyes evaluated by attenuated total reflection measurements. Colloids Surf A 198-200:917-922.

Ishikawa M, et al. 1998. Reflection-typeconfocal readout for multilayered optical memory. Opt Lett 23(22):1781-1783.

Ivanov M, Todorov T, Nikolova L, Tomova N, Dragostinova V. 1995. Photoinduced changes in the refractive index of azo-dye/polymer systems. Appl Phys Lett 66(17):2174-2176.

Ivanov M, et al. 2000. Light-induced optical activity in optically ordered amorphous sidechain azobenzene containing polymer. J Mod Opt 47(5):861-867.

Izumi A, Teraguchi M, Nomura R, Masuda T. 2000a. Synthesis of conjugated polymers with azobenzene moieties in the main chain. J Polym Sci, Part A 38(7):1057-1063.

Izumi A, Teraguchi M, Nomura R, Masuda T. 2000b. Synthesis of poly(p-phenylene)based photoresponsive conjugated polymers having azobenzene units in the main chain. Macromolecules 33(15):5347-5352.

Ji HF, et al. 2004. Photon-driven nanomechanical cyclic motion. Chem Commun (22):2532-2533.

Jiang D-L, Aida T. 1997. Photoisomerization in dendrimers by harvesting of low-energy photons. Nature 388(6641):454-456.

Jiang WH, et al. 2005. Photo-switched wettability on an electrostatic self-assembly azobenzene monolayer. Chem Commun (Cambridge, UK ) (28):3550-3552.

Jiang XL, Li L, Kumar J, Tripathy SK. 1996. Photoassisted poling induced second harmonic generation with in-plane anisotropy in azobenzene containing polymer films. Appl Phys Lett 69(24):3629-3631.

Jianhua G, et al. 1998. Surface plasmon resonance research on photoinduced switch properties of liquid crystalline azobenzene polymer Langmuir-Blodgett films. Supramol Sci 5(5-6):675-678.

Jin W, Shi X, Caruso F. 2001. High activity enzyme microcrystal multilayer films. J Am Chem Soc 123(33):8121-8122.

Jung B-D, et al. 2002. Photochromic hollow shells: photoisomerization of azobenzene polyionene in solution, in multilayer assemblies on planar and spherical surfaces. Colloids Surf A 198-200:483-489.

Jung JH, Takehisa C, Sakata Y, Kaneda T. 1996. p-(4-Nitrophenylazo)phenol dye-bridged permethylated a-cyclodextrin dimer: synthesis and self-aggregation in dilute aqueous solution. Chem Lett (2):147-148.

Junge DM, McGrath DV. 1997. Photoresponsive dendrimers. Chem Commun (9):857-858. 
Junge DM, McGrath DV. 1999. Photoresponsive azobenzene-containing dendrimers with multiple discrete states. J Am Chem Soc 121(20):4912-4913.

Jursic BS. 1996. Ab initio and density functional theory study of the diazene isomerization. Chem Phys Lett 261(1-2):13-17.

Kano K, et al. 1980. Photoresponsive membranes. Regulation of membrane properties by photoreversible cis-trans isomerization of azobenzenes. Chem Lett (4):421-424.

Kato T, Hirota N, Fujishima A, Frechet JMJ. 1996. Supramolecular hydrogen-bonded liquid-crystalline polymer complexes. Design of side-chain polymers and a host-guest system by noncovalent interaction. J Polym Sci, Part A 34(1):57-62.

Kawata S, Kawata Y. 2000. Three-dimensional optical data storage using photochromic materials. Chem Rev 100(5):1777-1788.

Kerzhner BK, Kofanov VI, Vrubel TL. 1983. Photoisomerization of aromatic azo compounds adsorbed on a hydroxylated surface. Zhurnal Obshchei Khimii 53(10):2303-2306.

Kim DY, Tripathy SK, Li L, Kumar J. 1995. Laser-induced holographic surface relief gratings on nonlinear optical polymer films. Appl Phys Lett 66(10):1166-1168.

Kleideiter G, Sekkat Z, Kreiter M, Lechner MD, Knoll W. 2000. Photoisomerization of disperse red one in films of poly(methyl-methacrylate) at high pressure. J Mol Struct 521(1-3):167-178.

Kleinfeld ER, Ferguson GS. 1994. Stepwise formation of multilayered nanostructural films from macromolecular precursors. Science 265(5170):370-373.

Knoll W. 1996. Self-assembled microstructures at interfaces. Curr Opin Colloid Interface Sci 1(1):137-143.

Kobayashi T, Degenkolb EO, Rentzepis PM. 1979. Picosecond spectroscopy of 1phenylazo-2-hydroxynaphthalene. J Phys Chem 83(19):2431-2434.

Komori K, Yatagai K, Tatsuma T. 2004. Activity regulation of tyrosinase by using photoisomerizable inhibitors. J Biotechnol 108(1):11-16.

Kotov NA, Dekany I, Fendler JH. 1995. Layer-by-layer self-assembly of polyelectrolytesemiconductor nanoparticle composite films. J Phys Chem 99(35):13065-13069.

Kwolek S, Morgan P, Schaefgen J. 1985. Encyclopedia of Polymer Science and Engineering, 9. New York: John-Wiley.

Labarthet FL, Buffeteau T, Sourisseau C. 1998. Analyses of the diffraction efficiencies, birefringence, and surface relief gratings on azobenzene-containing polymer films. J Phys Chem B 102(15):2654-2662.

Lamarre L, Sung CSP. 1983. Studies of physical aging and molecular motion by azochromophoric labels attached to the main chains of amorphous polymers. Macromolecules 16(11):1729-1736.

Lednev IK, Ye T-Q, Hester RE, Moore JN. 1996. Femtosecond time-resolved UV-visible absorption spectroscopy of trans-azobenzene in solution. J Phys Chem 100(32): 13338-13341.

Lee S-H, et al. 2000. Azo polymer multilayer films by electrostatic self-assembly and layerby-layer post azo functionalization. Macromolecules 33(17):6534-6540.

Lee S-S, et al. 2001. Layer-by-layer deposited multilayer assemblies of ionene-type polyelectrolytes based on the spin-coating method. Macromolecules 34(16):5358-5360. 
Lee S-S, Lee K-B, Hong J-D. 2003. Evidence for spin coating electrostatic self-assembly of polyelectrolytes. Langmuir 19(18):7592-7596.

Lee TS, et al. 1998. Photoinduced surface relief gratings in high-Tg main-chain azoaromatic polymer films. J Polym Sci, Part A 36(2):283-289.

Lee W-S, Ueno A. 2001. Photocontrol of the catalytic activity of a beta-cyclodextrin bearing azobenzene and histidine moieties as a pendant group. Macromol Rapid Commun 22(6):448-450.

Levy D, Esquivias L. 1995. Sol-gel processing of optical and electrooptical materials. Adv Mater 7(2):120-129.

Li S, McGrath DV. 2000. Effect of macromolecular isomerism on the photomodulation of dendrimer properties. J Am Chem Soc 122(28):6795-6796.

Li Y, Deng Y, Tong X, Wang X. 2006. Formation of photoresponsive uniform colloidal spheres from an amphiphilic azobenzene-containing random copolymer. Macromolecules 39(3):1108-1115.

Liang X, et al. 2003. NMR Study on the photoresponsive DNA tethering an azobenzene. Assignment of the absolute configuration of two diastereomers and structure determination of their duplexes in the trans-form. J Am Chem Soc 125(52):16408-16415.

Lien L, Jaikaran DCJ, Zhang Z, Woolley GA. 1996. Photomodulated blocking of gramicidin ion channels. J Am Chem Soc 118(48):12222-12223.

Linford MR, Auch M, Möhwald H. 1998. Nonmonotonic effect of ionic strength on surface dye extraction during dye-polyelectrolyte multilayer formation. J Am Chem Soc 120(1):178-182.

Liu M, Asanuma H, Komiyama M. 2005. Azobenzene-tethered T7 promoter for efficient photoregulation of transcription. J Am Chem Soc 128(3):1009-1015.

Liu N, et al. 2004. Photoregulation of mass transport through a photoresponsive azobenzene-modified nanoporous membrane. Nano Lett 4(4):551-554.

Liu X-H, Bruce DW, Manners I. 1997. Novel calamitic side-chain metallomesogenic polymers with ferrocene in the backbone: synthesis and properties of thermotropic liquid-crystalline poly(ferrocenylsilanes). Chem Commun (3):289-290.

Liu ZF, Hashimoto K, Fujishima A. 1990. Photoelectrochemical information storage using an azobenzene derivative. Nature 347:658-660.

Liu ZF, Morigaki K, Enomoto T, Hashimoto K, Fujishima A. 1992. Kinetic studies on the thermal cis-trans isomerization of an azo compound in the assembled monolayer film. J Phys Chem 96(4):1875-1880.

Lösche M, Schmitt J, Decher G, Bouwman WG, Kjaer K. 1998. Detailed structure of molecularly thin polyelectrolyte multilayer films on solid substrates as revealed by neutron reflectometry. Macromolecules 31(25):8893-8906.

Luk Y-Y, Abbott NL. 2003. Surface-driven switching of liquid crystals using redox-active groups on electrodes. Science 301(5633):623-626.

Lvov Y, Ariga K, Onda M, Ichinose I, Kunitake T. 1997. Alternate assembly of ordered multilayers of $\mathrm{SiO}_{2}$ and other nanoparticles and polyions. Langmuir 13(23):6195-6203.

$\mathrm{Ma} \mathrm{H}$, et al. 2002. Highly efficient and thermally stable electro-optical dendrimers for photonics. Adv Funct Mater 12(9):565-574.

Magennis SW, Mackay FS, Jones AC, Tait KM, Sadler PJ. 2005. Two-photon-induced photoisomerization of an azo dye. Chem Mater 17(8):2059-2062. 
Malcolm BR, Pieroni O. 1990. The photoresponse of an azobenzene-containing poly(L-lysine) in the monolayer state. Biopolymers 29(6-7):1121-1123.

Malkin S, Fischer E. 1962. Temperature dependence of photoisomerization. Part II.1 Quantum yields of cis-trans isomerizations in azo-compounds. J Phys Chem 66(12):2482-2486.

Mallia VA, Tamaoki N. 2003. Photoresponsive vitrifiable chiral dimesogens: photo-thermal modulation of microscopic disordering in helical superstructure and glass-forming properties. J Mater Chem 13(2):219-224.

Mattoussi H, Rubner MF, Zhou F, Kumar J, Tripathy SK. 2000. Photovoltaic heterostructure devices made of sequentially adsorbed poly(phenylene vinylene) and functionalized C60. Appl Phys Lett 77(10):1540-1542.

Maxein G, Zentel R. 1995. Photochemical inversion of the helical twist sense in chiral polyisocyanates. Macromolecules 28(24):8438-8440.

McAloney RA, Dudnik V, Goh MC. 2003. Kinetics of salt-induced annealing of a polyelectrolyte multilayer film morphology. Langmuir 19(9):3947-3952.

Mekelburger HB, Rissanen K, Voegtle F. 1993. Repetitive synthesis of bulky dendrimersa reversibly photoactive dendrimer with six azobenzene side chains. Chem Ber 126(5):1161-1169.

Mendelsohn JD, et al. 2000. Fabrication of microporous thin films from polyelectrolyte multilayers. Langmuir 16(11):5017-5023.

Meng X, Natansohn A, Barrett C, Rochon P. 1996. Azo polymers for reversible optical storage. 10. Cooperative motion of polar side groups in amorphous polymers. Macromolecules 29(3):946-952.

Mermut O, Barrett CJ. 2001. Stable sensor layers self-assembled onto surfaces using azobenzene-containing polyelectrolytes. Analyst (Cambridge, UK) 126(11):1861-1865.

Mermut O, Barrett CJ. 2003. Effects of charge density and counterions on the assembly of polyelectrolyte multilayers. J Phys Chem B 107(11):2525-2530.

Mermut O, Lefebvre J, Gray DG, Barrett CJ. 2003. Structural and mechanical properties of polyelectrolyte multilayer films studied by AFM. Macromolecules 36(23):8819-8824.

Minoura N, et al. 2004. Preparation of azobenzene-containing polymer membranes that function in photoregulated molecular recognition. Macromolecules 37(25):9571-9576.

Mita I, Horie K, Hirao K. 1989. Photochemistry in polymer solids. 9. Photoisomerization of azobenzene in a polycarbonate film. Macromolecules 22(2):558-563.

Möhlmann G, van der Vorst C. 1989. Side Chain Liquid Crystal Polymers. Glasgow: Plenum and Hall.

Moller G, Harke M, Motschmann H, Prescher D. 1998. Controlling microdroplet formation by light. Langmuir 14(18):4955-4957.

Momotake A, Arai T. 2004a. Photochemistry and photophysics of stilbene dendrimers and related compounds. J Photochem Photobiol C 5(1):1-25.

Momotake A, Arai T. 2004b. Synthesis, excited state properties, and dynamic structural change of photoresponsive dendrimers. Polymer 45(16):5369-5390.

Montagnoli G, Pieroni O, Suzuki S. 1983. Control of peptide chain conformation by photoisomerising chromophores: Enzymes and model compounds. Polymer Photochem 3(4):279-294. 
Monti S, Orlandi G, Palmieri P. 1982. Features of the photochemically active state surfaces of azobenzene. Chem Phys 71(1):87-99.

Morino S, Kaiho A, Ichimura K. 1998. Photogeneration and modification of birefringence in crosslinked films of liquid crystal/polymer composites. Appl Phys Lett 73(10):1317-1319.

Müller M, Zentel R. 1996. Interplay of chiral side chains and helical main chains in polyisocyanates. Macromolecules 29(5):1609-1617.

Nagamani SA, Norikane Y, Tamaoki N. 2005. Photoinduced hinge-like molecular motion: studies on xanthene-based cyclic azobenzene dimers. J Org Chem 70(23):9304-9313.

Naito K, Miura A. 1993. Molecular design for nonpolymeric organic dye glasses with thermal stability: relations between thermodynamic parameters and amorphous properties. J Phys Chem 97(23):6240-6248.

Naito T, Horie K, Mita I. 1991. Photochemistry in polymer solids. 11. The effects of the size of reaction groups and the mode of photoisomerization on photochromic reactions in polycarbonate film. Macromolecules 24(10):2907-2911.

Naito T, Horie K, Mita I. 1993. Photochemistry in polymer solids: 12. Effects of mainchain structures and formation of hydrogen bonds on photoisomerization of azobenzene in various polymer films. Polymer 34(19):4140-4145.

Nakayama K, Endo M, Majima T. 2004. Photochemical regulation of the activity of an endonuclease BamHI using an azobenzene moiety incorporated site-selectively into the dimer interface. Chem Commun (Cambridge, UK) (21):2386-2387.

Nakayama K, Endo M, Majima T. 2005. A hydrophilic azobenzene-bearing amino acid for photochemical control of a restriction enzyme BamHI. Bioconjug Chem 16(6):1360-1366.

Natansohn A, Rochon P. 1999. Photoinduced motions in azobenzene-based amorphous polymers: possible photonic devices. Adv Mater 11(6):1387-1391.

Natansohn A, Rochon P. 2002. Photoinduced motions in azo-containing polymers. Chem Rev 102(11):4139-4176.

Natansohn A, Rochon P, Gosselin J, Xie S. 1992. Azo polymers for reversible optical storage. 1. Poly[4'-[[2-(acryloyloxy)ethyl]ethylamino]-4-nitroazobenzene]. Macromolecules 25(8):2268-2273.

Natansohn A, et al. 1994. Azo polymers for reversible optical storage. 4. Cooperative motion of rigid groups in semicrystalline polymers. Macromolecules 27(9):2580-2585.

Nikolova L, et al. 2000. Self-induced light polarization rotation in azobenzene-containing polymers. Appl Phys Lett 77(5):657-659.

Nikolova L, et al. 1996. Polarization holographic gratings in side-chain azobenzene polyesters with linear and circular photoanisotropy. Appl Opt 35(20):3835-3840.

Nikolova L, et al. 1997. Photoinduced circular anisotropy in side-chain azobenzene polyesters. Opt Mater 8(4):255-258.

Neuert G, Hugel T, Netz RR, Gaub HE. 2005. Elasticity of poly(azobenzene-peptides). Macromolecules 39(2):789-797.

Norikane Y, Kitamoto K, Tamaoki N. 2003. Novel crystal structure, cis-trans isomerization, and host property of meta-substituted macrocyclic azobenzenes with the shortest linkers. J Org Chem 68(22):8291-8304.

Norman LL, Barrett CJ. 2002. Solution properties of self-assembled amphiphilic copolymers determined by isomerization spectroscopy. J Phys Chem B 106(34):8499-8503. 
Nunzi J-M, Fiorini C, Etilé A-C, Kajzar F. 1998. All-optical poling in polymers: dynamical aspects and perspectives. Pure Appl Opt 7(2):141-150.

Nyamjav D, Ivanisevic A. 2004. Properties of polyelectrolyte templates generated by dippen nanolithography and microcontact printing. Chem Mater 16(25):5216-5219.

Paik CS, Morawetz H. 1972. Photochemical and thermal isomerization of azoaromatic residues in the side chains and the backbone of polymers in bulk. Macromolecules 5(2):171-177.

Park M-K, Advincula RC. 2002. In-plane photoalignment of liquid crystals by azobenzenepolyelectrolyte layer-by-layer ultrathin films. Langmuir 18(11):4532-4535.

Pieroni O, Houben JL, Fissi A, Costantino P. 1980. Reversible conformational-changes induced by light in poly(L-glutamic acid) with photochromic side-chains. J Am Chem Soc 102(18):5913-5915.

Prasad SK, Nair GG. 2001. Effects of photo-controlled nanophase segregation in a reentrant nematic liquid crystal. Adv Mater 13(1):40-43.

Priest WJ, Sifain MM. 1971. Photochemical and thermal isomerization in polymer matrixes. Azo compounds in polystyrene. J Polym Sci, Part A 9(11):3161-3168.

Ramanujam PS, et al. 2001. Physics and technology of optical storage in polymer thin films. Synth Met 124(1):145-150.

Rau H. 1968. Radiationless deactivation of azo compounds and light fastness of azo dyes. Berichte der Bunsen-Gesellschaft 72(3):408-414.

Rau H. 1990. Photoisomerization of Azobenzenes. In: Rebek J, editor. Photochemistry and Photophysics. Boca Raton (FL): CRC Press, p. 119-141.

Rau H, Lueddecke E. 1982. On the rotation-inversion controversy on photoisomerization of azobenzenes. Experimental proof of inversion. J Am Chem Soc 104(6):1616-1620.

Rau H, Roettger D. 1994. Photochromic azobenzenes which are stable in the trans and cis forms. Mol Cryst Liq Cryst Sci Technol, A 246:143-146.

Rau H, Crosby AD, Schaufler A, Frank R. 1981. Triplet-sensitized photoreaction of azobenzene in sulfuric-acid. Z Naturforsch, A: Phys Sci 36(11):1180-1186.

Rau H, Greiner G, Gauglitz G, Meier H. 1990. Photochemical quantum yields in the A-B system when only the spectrum of A is known. J Phys Chem 94(17):6523-6524.

Razna J, Hodge P, West D, Kucharski S. 1999. NLO properties of polymeric LangmuirBlodgett films of sulfonamide-substituted azobenzenes. J Mater Chem 9(8):1693-1698.

Reynier N, Dozol J-F, Saadioui M, Asfari Z, Vicens J. 1998. Complexation properties of a new photosensitive calix[4]arene crown ether containing azo unit in the lower rim towards alkali cations. Tetrahedron Lett 39(36):6461-6464.

Richert L, et al. 2002. Cell interactions with polyelectrolyte multilayer films. Biomacromolecules 3(6):1170-1178.

Rmaile HH, Schlenoff JB. 2003. Optically active polyelectrolyte multilayers as membranes for chiral separations. J Am Chem Soc 125(22):6602-6603.

Rochon P, Batalla E, Natansohn A. 1995. Optically induced surface gratings on azoaromatic polymer films. Appl Phys Lett 66(2):136-138.

Rottger D, Rau H. 1996. Photochemistry of azobenzenophanes with three-membered bridges. J Photochem Photobiol A Chem 101(2-3):205-214.

Rouse JH, Ferguson GS. 2002. Stepwise incorporation of nonpolar polymers within polyelectrolyte multilayers. Langmuir 18(20):7635-7640. 
Ruslim C, Ichimura K. 2001. Conformation-assisted amplification of chirality transfer of chiral Z-azobenzenes. Adv Mater 13(1):37-40.

Sabi Y, et al. 2001. Photoaddressable polymers for rewritable optical disk systems. Jpn J Appl Phys, Part 1 40(3B):1613-1618.

Sackmann E. 1971. Photochemically induced reversible color changes in cholesteric liquid crystals. J Am Chem Soc 93(25):7088-7090.

Saremi F, Tieke B. 1998. Photoinduced switching in self-assembled multilayers of an azobenzene bolaamphiphile and polyelectrolytes. Adv Mater 10(5):389-391.

Sarkar N, Sarkar A, Sivaram S. 2001. Isomerization behavior of aromatic azo chromophores bound to semicrystalline polymer films. J Appl Polym Sci 81(12):2923-2928.

Sata T, Shimokawa Y, Matsusaki K. 2000. Preparation of ion-permeable membranes having an azobenzene moiety and their transport properties in electrodialysis. J Membr Sci 171(1):31-43.

Schulze FW, Petrick HJ, Cammenga HK, Klinge H. 1977. Thermodynamic properties of the structural analogs benzo[c]cinnoline, trans-azobenzene, and cis-azobenzene. Z Phys Chem (Muenchen, Ger) 107(1):1-19.

Seki T, et al. 1993. "Command surfaces" of Langmuir-Blodgett films. Photoregulations of liquid crystal alignment by molecularly tailored surface azobenzene layers. Langmuir 9(1):211-218.

Sekkat Z, Kang C-S, Aust EF, Wegner G, Knoll W. 1995a. Room-temperature photoinduced poling and thermal poling of a rigid main-chain polymer with polar azo dyes in the side chain. Chem Mater 7(1):142-147.

Sekkat Z, Wood J, Knoll W. 1995b. Reorientation mechanism of azobenzenes within the trans-cis photoisomerization. J Phys Chem 99(47):17226-17234.

Shannon PJ, Gibbons WM, Sun ST. 1994. Patterned optical properties in photopolymerized surface-aligned liquid-crystal films. Nature 368(6471):532-533.

Shen YQ, Rau H. 1991. The environmentally controlled photoisomerization of probe molecules containing azobenzene moieties in solid poly(methyl methacrylate). Macromol Chem Phys 192(4):945-957.

Shi Y, Steier WH, Yu L, Chen M, Dalton LR. 1991a. Large photoinduced birefringence in an optically nonlinear polyester polymer. Appl Phys Lett 59(23):2935-2937.

Shi Y, Steier WH, Yu L, Chen M, Dalton LR. 1991b. Large stable photoinduced refractive index change in a nonlinear optical polyester polymer with disperse red side groups. Appl Phys Lett 58(11):1131-1133.

Shibaev V, Bobrovsky A, Boiko N. 2003. Photoactive liquid crystalline polymer systems with light-controllable structure and optical properties. Prog Polym Sci 28:729-836.

Shinkai S, Minami T, Kusano Y, Manabe O. 1983. Photoresponsive crown ethers. 8. Azobenzenophane-type switched-on crown ethers which exhibit an all-or-nothing change in ion-binding ability. J Am Chem Soc 105(7):1851-1856.

Shiratori SS, Rubner MF. 2000. pH-Dependent thickness behavior of sequentially adsorbed layers of weak polyelectrolytes. Macromolecules 33(11):4213-4219.

Shirota Y, Moriwaki K, Yoshikawa S, Ujike T, Nakano H. 1998. 4-[Di(biphenyl-4yl)amino]azobenzene and 4,4'-bis[bis(4'-tert-butylbiphenyl-4-yl)amino]azobenzene as a novel family of photochromic amorphous molecular materials. J Mater Chem 8(12):2579-2581. 
Shishido A, et al. 1997. Rapid optical switching by means of photoinduced change in refractive index of azobenzene liquid crystals detected by reflection-mode analysis. J Am Chem Soc 119(33):7791-7796.

Siewierski LM, Brittain WJ, Petrash S, Foster MD. 1996. Photoresponsive monolayers containing in-chain azobenzene. Langmuir 12(24):5838-5844.

Silva JR, Dall'Agnol FF, Oliveira ON Jr., Giacometti JA. 2002. Temperature dependence of photoinduced birefringence in mixed Langmuir-Blodgett (LB) films of azobenzenecontaining polymers. Polymer 43(13):3753-3757.

Singh AK, Das J, Majumdar N. 1996. Novel bacteriorhodopsin analogs based on azo chromophores. J Am Chem Soc 118(26):6185-6191.

Sisido M, Ishikawa Y, Harada M, Itoh K. 1991a. Helically arranged azobenzene chromophores along a polypeptide chain. 2. Prediction of conformations and calculation of theoretical circular dichroism. Macromolecules 24(14):3999-4003.

Sisido M, Ishikawa Y, Itoh K, Tazuke S. 1991b. Helically arranged azobenzene chromophores along a polypeptide chain. 1. Synthesis and circular dichroism. Macromolecules 24(14):3993-3998.

Spörlein S, et al. 2002. Ultrafast spectroscopy reveals subnanosecond peptide conformational dynamics and validates molecular dynamics simulation. Proc Natl Acad Sci USA 99(12):7998-8002.

Steenwinckel DV, Hendrickx E, Persoons A. 2001. Large dynamic ranges in photorefractive NLO polymers and NLO-polymer-dispersed liquid crystals using a bifunctional chromophore as a charge transporter. Chem Mater 14(4):1230-1237.

Steinem C, Janshoff A, Vollmer MS, Ghadiri MR. 1999. Reversible photoisomerization of self-organized cylindrical peptide assemblies at air-water and solid interfaces. Langmuir 15(11):3956-3964.

Steitz R, Leiner V, Siebrecht R, Klitzing Rv. 2000. Influence of the ionic strength on the structure of polyelectrolyte films at the solid/liquid interface. Colloids Surf A 163(1):63-70.

Stiller B, et al. 1999. Self-assembled monolayers of novel azobenzenes for optically induced switching. Mater Sci Eng C 8-9:385-389.

Stumpe J, et al. 1991. Photoreaction in mesogenic media. 5. Photoinduced optical anisotropy of liquid-crystalline side-chain polymers with azochromophores by linearly polarized light of low intensity. Makromol Chem, Rapid Commun 12(2):81-87.

Sukhorukov GB, Schmitt J, Decher G. 1996. Reversible swelling of polyanion/polycation multilayer films in solutions of different ionic strength. Berichte der Bunsen-Gesellschaft 100(6):948-953.

Sukhorukov GB, et al. 1998a. Stepwise polyelectrolyte assembly on particle surfaces: a novel approach to colloid design. Polym Adv Technol 9(10-11):759-767.

Sukhorukov GB, et al. 1998b. Layer-by-layer self assembly of polyelectrolytes on colloidal particles. Colloids Surf A 137(1-3):253-266.

Sukwattanasinitt M, et al. 1998. Functionalizable self-assembling polydiacetylenes and their optical properties. Chem Mater 10(1):27-29.

Sumaru K, Inui S, Yamanaka T. 1999. Preliminary investigation of self-organization pattern mapping system based on photochromism. Opt Eng 38(2):274-283. 
Sun ST, Gibbons WM, Shannon PJ. 1992. Alignment of guest-host liquid crystals with polarized laser light. Liq Cryst 12(5):869-874.

Suzuki I, Sato K, Koga M, Chen Q, Anzai J-I. 2003. Polyelectrolyte layered assemblies containing azobenzene-modified polymer and anionic cyclodextrins. Mater Sci Eng C 23(5):579-583.

Tanaka K, Tateishi Y, Nagamura T. 2004. Photoisomerization of azobenzene probes tagged to polystyrene in thin films. Macromolecules 37(22):8188-8190.

Tang Z, Kotov NA, Magonov S, Ozturk B. 2003. Nanostructured artificial nacre. Nat Mater 2:413-418.

Tawa K, Knoll W. 2002. Out-of-plane photoreorientation of azo dyes in polymer thin films studied by surface plasmon resonance spectroscopy. Macromolecules 35(18):7018-7023.

Teraguchi M, Masuda T. 2000. Synthesis and properties of polyacetylenes having azobenzene pendant groups. Macromolecules 33(2):240-242.

Thierry B, Winnik FM, Merhi Y, Tabrizian M. 2003. Nanocoatings onto arteries via layerby-layer deposition: toward the in vivo repair of damaged blood vessels. J Am Chem Soc 125(25):7494-7495.

Tokuhisa H, Yokoyama M, Kimura K. 1994. Photoresponsive ion-conducting behavior of polysiloxanes carrying a crowned azobenzene moiety at the side chain. Macromolecules 27(7):1842-1846.

Toutianoush A, Tieke B. 1998. Photoinduced switching in self-assembled multilayers of azobenzene-containing ionene polycations and anionic polyelectrolytes. Macromol Rapid Commun 19(11):591-595.

Toutianoush A, Saremi F, Tieke B. 1999. Photoinduced switching in self-assembled multilayers of ionenes and bolaamphiphiles containing azobenzene units. Mater Sci Eng C C8-C9:343-352.

Tsuchiya S. 1999. Intramolecular electron transfer of diporphyrins comprised of electrondeficient porphyrin and electron-rich porphyrin with photocontrolled isomerization. J Am Chem Soc 121(1):48-53.

Tsutsumi N, Yoshizaki S, Sakai W, Kiyotsukuri T. 1996. Thermally stable nonlinear optical polymers. MCLC S\&T, Section B: Nonlinear Optics 15(1-4):387-390.

Uznanski P, Pecherz J. 2002. Surface plasmon resonance of azobenzene-incorporated polyelectrolyte thin films as an $\mathrm{H}+$ indicator. J Appl Polym Sci 86(6):1459-1464.

Uznanski P, Kryszewski M, Thulstrup EW. 1991. Linear dichroism and trans-cis photoisomerization studies of azobenzene molecules in oriented polyethylene matrix. Eur Polym J 27(1):41-43.

Van Cott KE, et al. 2002. Layer-By-layer deposition and ordering of low-molecular-weight dye molecules for second-order nonlinear optics. Angew Chem Int Ed 41(17):3236-3238.

Villavicencio O, McGrath DV. 2002. Azobenzene-containing dendrimers. Advances in Dendritic Macromolecules 5:1-44.

Viswanathan NK, et al. 1999. Surface relief structures on azo polymer films. J Mater Chem 9(9):1941-1955.

Voinova MV, Jonson M. 2004. Electronic transduction in model enzyme sensors assisted by a photoisomerizable azo-polymer. Biosens Bioelectron 20(6):1106-1110.

Vollmer MS, Clark TD, Steinem C, Ghadiri MR. 1999. Photoswitchable hydrogen-bonding in self-organized cylindrical peptide systems. Angew Chem Int Ed 38(11):1598-1601. 
Wang H, He Y, Tuo X, Wang X. 2004. Sequentially adsorbed electrostatic multilayers of branched side-chain polyelectrolytes bearing donor-acceptor type azo chromophores. Macromolecules 37(1):135-146.

Wang L, Schultz PG. 2004. Expanding the genetic code. Angew Chem Int Ed 44(1):34-66.

Wang TC, Rubner MF, Cohen RE. 2002. Polyelectrolyte multilayer nanoreactors for preparing silver nanoparticle composites: controlling metal concentration and nanoparticle size. Langmuir 18(8):3370-3375.

Wang X, et al. 1997a. Self-assembled second order nonlinear optical multilayer azo polymer. Macromol Rapid Commun 18(6):451-459.

Wang X, et al. 1997b. Epoxy-based nonlinear optical polymers functionalized with tricyanovinyl chromophores. Chem Mater 9(1):45-50.

Wang X, et al. 1997c. Epoxy-based nonlinear optical polymers from post azo coupling reaction. Macromolecules 30(2):219-225.

Wang X, Balasubramanian S, Kumar J, Tripathy SK, Li L. 1998. Azo chromophorefunctionalized polyelectrolytes. 1. Synthesis, characterization, and photoprocessing. Chem Mater 10(6):1546-1553.

Watanabe O, Tsuchimori M, Okada A. 1996. Two-step refractive index changes by photoisomerization and photobleaching processes in the films of nonlinear optical polyurethanes and a urethane-urea copolymer. J Mater Chem 6(9):1487-1492.

Watanabe S, Regen SL. 1994. Dendrimers as building blocks for multilayer construction. J Am Chem Soc 116(19):8855-8856.

Weh K, et al. 1998. Modification of the transport properties of a polymethacrylateazobenzene membrane by photochemical switching. Chem Eng Technol 21(5):408-412.

Weiss RG, Ramamurthy V, Hammond GS. 1993. Photochemistry in organized and confining media: a model. Acc Chem Res 25(10):530-536.

Wiesner U, Reynolds N, Boeffel C, Spiess HW. 1991. Photoinduced reorientation in liquidcrystalline polymers below the glass transition temperature studied by time-dependent infrared spectroscopy. Makromol Chem, Rapid Commun 12(8):457-464.

Willner I, Rubin S. 1993. Reversible photoregulation of the activities of proteins. Reactive Polymers 21(3):177-186.

Willner I, Rubin S. 1996. Control of the structure and functions of biomaterials by light. Angew Chem Int Ed Engl 35(4):367-385.

Willner I, Willner B. 1997. Molecular optoelectronic systems. Adv Mater 9(4):351-355.

Willner I, Rubin S, Riklin A. 1991a. Photoregulation of papain activity through anchoring photochromic azo groups to the enzyme backbone. J Am Chem Soc 113(9):3321-3325.

Willner I, Rubin S, Zor T. 1991b. Photoregulation of alpha-chymotrypsin by its immobilization in a photochromic azobenzene copolymer. J Am Chem Soc 113(10):4013-4014.

Willner I, Rubin S, Shatzmiller R, Zor T. 1993. Reversible light-stimulated activation and deactivation of alpha-chymotrypsin by its immobilization in photoisomerizable copolymers. J Am Chem Soc 115(19):8690-8694.

Wu L, Tuo X, Cheng H, Chen Z, Wang X. 2001a. Synthesis, photoresponsive behavior, and self-assembly of poly(acrylic acid)-based azo polyelectrolytes. Macromolecules 34(23):8005-8013. 
Wu Y, Natansohn A, Rochon P. 2001b. Photoinduced birefringence and surface relief gratings in novel polyurethanes with azobenzene groups in the main chain. Macromolecules 34(22):7822-7828.

Wuerthner F, Rebek J, Jr. 1995. Light-switchable catalysis in synthetic receptors. Angew Chem Int Ed Engl 34(4):446-450.

Xie S, Natansohn A, Rochon P. 1993. Recent developments in aromatic azo polymers research. Chem Mater 5(4):403-411.

Xu Z-S, Drnoyan V, Natansohn A, Rochon P. 2000. Novel polyesters with amino-sulfone azobenzene chromophores in the main chain. J Polym Sci, Part A 38(12):2245-2253.

Yager KG, Barrett CJ. 2001. All-optical patterning of azo polymer films. Curr Opin Solid State Mater Sci 5(6):487-494.

Yamaki S, Nakagawa M, Morino S, Ichimura K. 2000. Surface relief gratings generated by a photocrosslinkable polymer with styrylpyridine side chains. Appl Phys Lett 76(18):2520-2522.

Yamamoto H. 1986. Synthesis and reversible photochromism of azo aromatic poly(L-lysine). Macromolecules 19(10):2472-2476.

Yamamoto H, Nishida A. 1991. Photoresponsive peptide and polypeptide systems. Part 9. Synthesis and reversible photochromism of azo aromatic poly(L-a,g-diaminobutyric acid). Polym Int 24(3):145-148.

Yamamoto H, Nishida A, Takimoto T, Nagai A. 1990. Photoresponsive peptide and polypeptide systems. VIII. Synthesis and reversible photochromism of azo aromatic poly(L-ornithine). J Polym Sci, Part A: Polym Chem 28(1):67-74.

Yamamoto T, et al. 2001. Phase-type gratings formed by photochemical phase transition of polymer azobenzene liquid crystal. 2. Rapid switching of diffraction beams in thin films. J Phys Chem B 105(12):2308-2313.

Yamamura $\mathrm{H}$, et al. 1996. A cyclodextrin derivative with cation carrying ability: heptakis(3,6-anhydro)-b-cyclodextrin 2-O-p-phenylazobenzoate. Chem Lett(9):799-800.

Yamane H, Kikuchi H, Kajiyama T. 1999. Laser-addressing rewritable optical information storage of (liquid crystalline side chain copolymer/liquid crystals/photo-responsive molecule) ternary composite systems. Polymer 40(17):4777-4785.

Yang L, Takisawa N, Hayashita T, Shirahama K. 1995. Colloid chemical characterization of the photosurfactant 4-Ethylazobenzene 4'-(Oxyethyl)trimethylammonium Bromide. J Phys Chem 99(21):8799-8803.

Yaroschuk O, et al. 2001. Light induced structures in liquid crystalline side-chain polymers with azobenzene functional groups. J Chem Phys 114(12):5330-5337.

Yesodha SK, Pillai CKS, Tsutsumi N. 2004. Stable polymeric materials for nonlinear optics: a review based on azobenzene systems. Prog Polym Sci 29:45-74.

Yitzchaik S, Marks TJ. 1996. Chromophoric self-assembled superlattices. Acc Chem Res 29(4):197-202.

Yokoyama S, Nakahama T, Otomo A, Mashiko S. 2000. Intermolecular coupling enhancement of the molecular hyperpolarizability in multichromophoric dipolar dendrons. J Am Chem Soc 122(13):3174-3181.

Yu Y, Nakano M, Ikeda T. 2003. Photomechanics: Directed bending of a polymer film by light. Nature 425:145. 
Yu YL, Ikeda T. 2004. Alignment modulation of azobenzene-containing liquid crystal systems by photochemical reactions. J Photochem Photobiol C: Photochem Rev 5(3):247-265.

Yu YL, Nakano M, Maeda T, Kondo M, Ikeda T. 2005. Precisely direction-controllable bending of cross-linked liquid-crystalline polymer films by light. Mol Cryst Liq Cryst 436:1235-1244.

Zawisza I, Bilewicz R, Luboch E, Biernat JF. 1999. Properties of Z and E isomers of azocrown ethers in monolayer assemblies at the air-water interface. Thin Solid Films 348(1-2):173-179.

Zhai L, Cebeci FÇ, Cohen RE, Rubner MF. 2004. Stable superhydrophobic coatings from polyelectrolyte multilayers. Nano Lett 4(7):1349-1353.

Zhong X, et al. 2001. Identification of the alignment of azobenzene molecules induced by all-optical poling in polymer films. Opt Commun 190(1-4):333-337.

Ziegler A, Stumpe J, Toutianoush A, Tieke B. 2002. Photoorientation of azobenzene moieties in self-assembled polyelectrolyte multilayers. Colloids Surf A 198-200:777-784.

Zilker SJ, et al. 1998. Holographic data storage in amorphous polymers. Adv Mater 10(11):855-859.

Zollinger H. 1961. Azo and Diazo Chemistry. New York: Interscience.

Zollinger H. 1987. Colour Chemistry, Synthesis, Properties, and Applications of Organic Dyes. Weinheim: VCH. 